\title{
PLANT TISSUE AND CELL CULTURE IN VIETNAM: FORTY-FIVE YEARS OF DEVELOPMENT AND THE FUTURE
}

\author{
Nguyen Duc Thanh \\ Institute of Biotechnology, VAST
}

Received 13 February 2020, accepted 28 July 2020

\begin{abstract}
By 2020, plant tissue and cell culture in Vietnam had undergone 45 years of research and development. For nearly half a century, plant tissue and cell culture has been developed to its full potential, especially with the development of genetics, biochemistry and molecular biology. It has contributed significantly to basic and practical researches in our country. In addition to contributions to domestic science and technology, plant tissue and cell culture in Vietnam has also made impressive imprints in the development of plant tissue and cell culture in the world. In this review, I will summarize the process of formation, development and important achievements as well as the challenges and future prospects of this potential field in Vietnam to provide information for researchers, managers, graduate students and other interested readers.
\end{abstract}

Keywords: Achievement, contribution, development, plant tissue and cell culture, Vietnam.

Citation: Nguyen Duc Thanh, 2020. Plant tissue and cell culture in Vietnam: forty-five years of development and the future. Academia Journal of Biology, 42(3): 53-88. https://doi.org/10.15625/2615-9023/v42n3.14824.

Corresponding author email: nguyenducthanh_pcg@ibt.ac.vn

(C2020 Vietnam Academy of Science and Technology (VAST) 


\section{INTRODUCTION}

Plant tissue and cell culture (PTCC) includes techniques for culturing plant cells, tissues and organs under aseptic conditions on artificial media with known nutritional components. These techniques have been approached by Vietnamese scientists since the $70 \mathrm{~s}$ of the twentieth century due to their high potential for research and practical applications. Materials used in PTCC include: organs (shoot, root, anthers...), tissues and cells. Types of culture include: meristem culture, callus culture, cell culture (single cell, protoplast), embryonic culture, anther culture, pollen culture, thin cell layer culture (TCLC), etc. The basic culture methods are: culture on solid medium, culture in liquid medium (static or shaking), culture on semi-liquid medium. The main PTCC techniques include: micropropagation (or in vitro propagation), haploid plant production, somatic cell hybridization, embryo rescue, cell line selection and gene transfer.

PTCC is widely used in micropropagation of agricultural, forestry and flower plants as well as in the conservation of rare or endangered plant species. PTCC can be used for screening at the cellular level instead of selecting plants with beneficial traits such as disease resistance and tolerance to adverse environmental conditions. Large-scale cultivation of plant cells through liquid culture in bioreactor can generate biomass to obtain secondary substances and recombinant proteins used as biopharmaceuticals. Through PTCC, it is possible to create hybrid plants using fusion of protoplasts or rescue embryos of distant hybrid combinations. Producing haploid plants from anthersor pollen culture allows the creation of homozygous lines faster in breeding programs. Transgenic plants that express genes from animals, bacteria, viruses or other plant genes that lead to production of vaccines, recombinant proteins, plants resistant to insects, viruses and other pathogens, and crops with high nutritional quality.

In this review, the process of formation, development and important achievements as well as the challenges and future prospects of PTCC in Vietnam will be presented. The information is based on works done in Vietnam that have been published in the conference proceedings, scientific journals and prestigious monographs in the country and abroad.

\section{FORMATION AND DEVELOPMENT}

Since before 1975, Dr. Nguyen Van Uyen, Dr. Le Thi Muoi, Le Thi Xuan, Tran Ngoc Cat were the first officials to have an idea to set up a PTCC laboratory in Vietnam. After the complete liberation of the South and reunifying of the country (1975), Dr. Nguyen Van Uyen and a number of other researchers such as Trinh Manh Dung and Phan Xuan Thanh were assigned to the Vietnam Science Institute in Ho Chi Minh City to set up a PTCC laboratory here, later expanded to Da Lat and other localities. Especially, in vitro propagation of potato in "family laboratories" and the production of potato seedlings in pots were implemented by using potato seeding techniques in Da Lat. In addition, scientists in the South also studied the propagation of orchids (Huynh Van Hai, Nguyen Van Uyen, 1981; Mai Thi Phuong Hoa et al., 2011; Bui Thi Tuong, Tran Van Minh, 2011), anther culture of rice (Trinh Manh Dung et al., 1986), culture of apical buds of taro plant (Nguyen Thi Quynh \& Nguyen Van Uyen, $1985 ; 1987$ ), protoplast culture (Nguyen Thi Lien Chi, Nguyen Van Uyen, 1989) gene transfer (Nguyen Thi Thanh et al., 1997; Tran Thi Dung \& Nguyen Huu Ho, 2003) and research on propagation of some other plants such as coffee (Nguyen Thi Quynh, Nguyen Van Uyen, 1993a; 1993b), Artocarpus heterophyllus Lam. (Tran Van Minh, 1997), Polyscias fruticosa (Nguyen Ngoc Dung \& Nguyen Van Uyen, 1997), Azadirachta indica (Vu Ngoc Phuong et al., 2000), Paulownia fortune (Seem.) Hermsl (Doan Thi Ai Thuyen et al., 2001) and bamboo species (Vu Ngoc Phuong et al., 2002).

In the North, the PTCC research team included four staffs: Dr. Le Thi Muoi, Le Thi Xuan, Tran Ngoc Nguyen Hoang Uyen. In late 1975 and early 1976, Do Nang Vinh and 
Nguyen Duc Thanh graduated from Azerbaijan State University (in former Soviet Union) have joined the team. At that time, working conditions were inadequate and rudimentary; the main building of the Vietnam Scientific Institute was still under construction. However, due to news and modernity on PTCC, and the attention of the leaders of the Vietnam Scientific Institute, especially Prof. Nguyen Van Hieu, two rooms located on the second floor of the main building (rooms 207 and 208 buildings A2) were urgently completed to serve as plant cell culture laboratory. The culture box was originally made of wood with two holes on both sides covered by two cloth tubes, and the inside of the box was fitted with a UV light for sterilization. The UV light must turn on at least 30 minutes before the work and the transplanting time should not exceed one hour. The culture instruments and test tubes must be brought to the yard of the 1 st floor for washing. In addition, power and water outages often occur. However, even in 1976, the first success of PTCC in Vietnam was marked by the success of culturing rice pollen that was carried out by Do Nang Vinh and Nguyen Duc Thanh. In a diary written in Russian dated June 5, 1976 (Figure 1), Nguyen Duc Thanh wrote "Joy has come to us. We have received the tiny rice callus that we have been waiting for so long. We have been working for a long time with no results. And today it has arrived. When we grew tiny rice pollen in test tubes, we were certain that we would receive these calli. They are small but valuable to us. Because of them, we worked hard and waited until from the tiny anthers that inside were pollen grains that could only be seen under a magnification hundreds of times would grow into clumps of cells called "callus". We are very joyful and happy. For me, this is the first happiness on the scientific path. Oh! How soft, precious and sacred the calli are!". The laboratory led by Dr. Le Thi Muoi focused on the research and application of rice and tobacco anther culture techniques (Le Thi Muoi et al., 1978; Le Thi Xuan et al., 1978, 1979; Do Nang Vinh, 1979; Le Tran Binh, 1983; Nghiem Nhu Van, 1989), protoplast culture (Le Thi Muoi \& Nguyen Duc Thanh, 1978, Nguyen Duc Thanh, 1983; Le Thi Xuan, 1985), in vitro propagation (potato, carnation, bananas, sugarcane, agave, pineapple, medicinal plants, forestry trees, etc.), cell line selection (Nguyen Hoang Loc et al., 1990), cytoplasmic transfer (Nguyen Duc Thanh et al. , 1995, 1997; Le Tran Binh, 1991) and gene transfer (Tran Thi Phuong Lien \& Le Xuan Tu, 1993). Beside researching and applying PTCC techniques, the laboratory was also responsible for training researchers and technicians in this field for research institutes, universities and companies such as Agricultural University No. 1 (currently Vietnam National University of Agriculture), Institute of Medicinal Materials, Institute of Agricultural Science and Technology (currently Vietnam Academy of Agricultural Sciences), and Cao Bang Tobacco Company, etc. Later on, PTCC laboratories were also sat up in the above locations. Initially, these PTCC laboratories applied mainly in vitro propagation techniques for multiplication of potato and lily, callus culture and biomass production of medicinal plants, and anther culture to produce double haploid lines in rice.

In the Central region, after successful defence of PhD thesis at the PTCC laboratory of the Institute of Biology (currently the Institute of Biotechnology), Dr. Nguyen Hoang Loc returned to Hue University to setup a PTCC laboratory there. His research has focused on propagating a number of plants such as Aquilaria crassma Pierre (Nguyen Hoang Loc et al., 1997), Camellia japonica L (Nguyen Hoang Loc et al., 2001), applying PTCC to produce bioactive substance (Nguyen Hoang Loc et al., 2006) and expression of antigens in plants (Nguyen Hoang Loc et al., 2011).

The development of plant tissue and cell culture in Vietnam can be divided into three main stages:

1975-1985: This is the period of formation, approaching and mastering technologies and applying some PTCC techniques such as anther culture to produce 
double haploid lines and in vitro propagation for rapid propagation of potato, training research staff and technicians on PTCC for universities, research institutes and companies, establishing PTCC laboratories in some universities and research institutes.

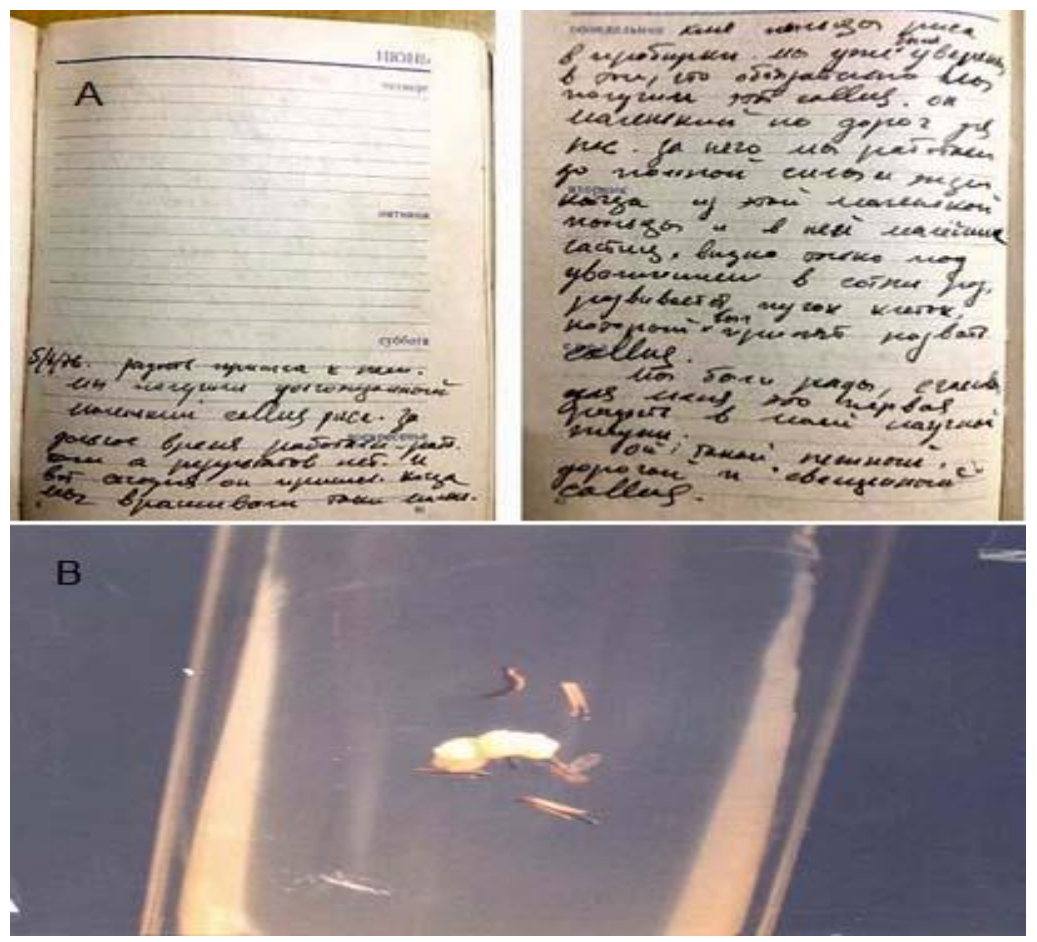

Figure 1. A. Nguyen Duc Thanh's Diary about the first success in Vietnam PTCC dated June 5, 1976; B. Callus tissue arising from rice anther culture

(Original photograph taken from a 1976 experiment)

1986-1995: This is the period of application and development of PTCC methods and techniques in research and practice, and, at the same time, establishing PTCC laboratories nationwide. In addition to in vitro propagation and anther culture techniques, a range of other techniques such as cell line selection, callus and suspension culture for biomass collection, protoplast culture and fusion, embryo rescue, gene transfer have been studied and applied.

1996-Present: This is the period to promote the development of biotechnology; in general, genetic engineering and plant cell technology, in particular, for the industrialization and modernization of the country. Studies and applications have been focusing on creating resilient crops; fast propagating food crops, vegetables, flowers, fruits, industrial trees and forest trees with good quality, high yield and tolerance to adverse external conditions as well as pests; conservation and development of rare and endangered genetic resources; research on expression of antigen, antibody and recombinant protein, gene transfer, thin cell layer (TCL) culture and photoautotrophic micropropagation.

\section{ACHIEVEMENTS}

\section{Basic research}

The basic research of PTCC in Vietnam mainly focuses on studying the factors affecting callus formation, plant regeneration, growth and development of different species under in vitro conditions, protoplast culture, TCL culture, cytoplasmic genetics, regeneration systems of different plants for 
transgenic transformation and expression of resistance-related genes, genes involved in yield and quality, and the genes encoding antibody and recombinant proteins.

Le Xuan Tu \& Nguyen Thi Xuan Giang (1981, 1982) studied the effects of gamma rays on the development of soybean callus, callus formation and plant regeneration from rice callus. The effects of gamma rays on regeneration of rice from mutated calli were also studied by Le Thi Bich Thuy et al. (2007). The conditions for culturing callus for biomass production of Maesa balansae Mez were investigated by Quach Thi Lien \& Nguyen Duc Thanh (2004). Duong Tan Nhut et al. (2009a) studied the effect of coconut water and sucrose on the growth of callus and formation of somatic embryos in Phalaenopsis amabilis (L.) Blume). Influence of culture conditions such as light, $\mathrm{CO}_{2}$ content (Nguyen Tri Minh et al., 2008; Duong Tan Nhut \& Nguyen Ba Nam, 2009, Do Thi Gam et al., 2017), sugars (Trinh Thi Lan Anh et al., 2013), growth regulators (Phan Duy Hiep et al., 2014; Vu Thi Lan et al., 2014), amino acids (Tran Trong Tuan et al., 2015), nano silver (Duong Tan Nhut et al., 2017a) in PTCC has been studied for in vitro propagation.

Le Thi Muoi \& Nguyen Duc Thanh (1978) for the first time in Vietnam announced the generation of a complete tobacco plants from protoplast. In 1980, Nguyen Duc Thanh \& Le Thi Muoi studied the effects of the composition and concentration of plant growth regulators on the process of generating complete tobacco plants from haploid protoplasts. Potato protoplasts were also successfully cultured and the complete plants were generated (Nguyen Duc Thanh \& Le Thi Muoi, 1981; Nguyen Duc Thanh, 1983, Nguyen Thi Phuong Thao et al., 2012). These results provided an important basis for further research on cytoplasmic transformation, chloroplast genetics and gene transfer. In addition, protoplasts of Arabidopsis thaliana (Le Thi Xuan, 1985), Solanum laciniatum
(Nguyen Thi Lien Chi \& Nguyen Van Uyen, 1989) have also been successfully cultured.

The use of cell technology in cytoplasmic genetics research, especially the use of protoplasts has achieved impressive results in transferring cytoplasmic male sterility (CMS) into tobacco plants (Nguyen Duc Thanh \& Medgyesy, 1988; Le Tran Binh, 1991), transferring whole chloroplasts or chloroplast genes (Nguyen Duc Thanh \& Medgyesy, 1989; Nguyen Duc Thanh \& Medgyesy, 1993; Nguyen Duc Thanh et al., 1995, 1997; Nghiem Ngoc Minh et al., 1999), creating chloroplast combinations in tobacco by fusion of protoplasts (Nguyen Duc Thanh et al., 1996), and producing cytoplasmic hybrid plants (Nghiem Ngoc Minh et al., 1997). The cytoplasmic genetic research using protoplasts is the unique research area that had only been conducted at the Institute of Biology (currently the Institute of Biotechnology, Vietnam Academy of Science and Technology) from the $80^{\text {th }}$ and $90^{\text {th }}$ of the twentieth century in Vietnam. Protoplasts were also used for the gene transfer into Brassica plants (Pham Thi Ly Thu et al., 2001; Pham Thi Ly Thu \& Le Huy Ham, 2003).

The research team of the Institute of Biology in Da Lat belongs to the Institute of Tropical Biology in Ho Chi Minh City, the National Center for Natural Sciences and Technology (currently the Tay Nguyen Scientific Research Institute, Vietnam Academy of Science and Technology) has studied the method of culturing TCL in lilies (Duong Tan Nhut et al., 2006b) and cauliflower (Duong Tan Nhut \& Bui Van The Vinh, 2009) and has been applied to propagate various plants such as lilies, Jatropha curcas, Ngoc Linh ginseng, and orchids (Duong Tan Nhut et al., 2008b; Do Dang Giap et al., 2012a; Vu Thi Hien et al., 2015; Vu Thi Hien et al., 2016; Nguyen Thi Kim Loan et al., 2016). TCL culture was also conducted at the Institute of Agricultural Biology for in vitro propagation of lilies and orchids (Nguyen Quang Thach \& Hoang Thi Nga, 2000; 
Nguyen Phuong Thao \& Nguyen Quang Thach 2005; Nguyen Thanh Tung et al., 2010).

A very important basic research direction is the research on plant regeneration systems of different plants for gene transfer, as regeneration systems are very important for plant transformation. If complete plants cannot be regenerated after the transgenic process, no transgenic crops could be produced. Therefore, many plants have been studied to regenerate plants from different tissues for transgenic studies. Green bean (Mai Truong et al., 2001), rice (Cao Le Quyen et al., 2011), maize (Nguyen Van Dong et al., 2009; Vu Thi Bich Huyen et al., 2013), peanut (Bui Van Thang et al., 2004; Nguyen Thi Thu Nga \& Le Tran Binh, 2012), tomato (Do Xuan Dong et al., 2007), papaya (Le Quynh Lien et al., 2003, Nguyen Minh Hung et al., 2006), Citrus nobilis Loureiro (Do Tien Phat et al., 2007), and Melia azedarach (Do Xuan Dong et al., 2008) regeneration systems were developed for gene transfer purpose.

Studies on expression of genes related to plant tolerance, yield and quality, and genes for antigen and recombinant proteins have been studied through PTCC in a number of laboratories in the Institute of Biotechnology, Institute of Tropical Biology, Institute of Agricultural Genetics, etc. NAC2 gene from L12 peanut cultivar coding for protein related to drought tolerance was expressed in tobacco plants (Nguyen Thi Thu Nga et al., 2015). Other genes related to drought tolerance in plants such as GmHKO6, GmRR34, and transcription factors like GmNAC092, GmNAC083, GmNAC057 were successfully expressed in soybeans (Hoang Thi Lan Xuan et al., 2015; Nguyen Binh An Thu et al., 2015). Insect resistance gene $\operatorname{cryIA}(c)$ was expressed in tobacco (Huynh Thi Thu Hue et al., 2008). Many studies have been conducted to express antigens in plants such as: VP2 antigen gene that induces an immune response in chickens in duckweed (Le Huy Ham et al., 2009), HA antigen of H5N1 virus in soybean seed (Nguyen Thu Hien et al., 2013), antigen GP5 of PRRS virus in tobacco (Dao Thi Sen et al., 2016), $\mathrm{H} 7$ antigen of influenza A/H7N9 virus in Nicotiana benthamiana (Le Thi Thuy et al., 2017). Recombinant protein interleukin7, a major regulator of the human immune system (Nguyen Huy Hoang et al., 2017), rabies glycoprotein (Le Quynh Lien et al., 2008) and protein M of PRRS virus causing blue ear disease (Nguyen Thi Minh Hang et al., 2018) were, successfully, expressed in Nicotiana plants. HIV-1-p24 gene, also, expressed in tomato-Lycopersicon esculentum Mill. (Phan Duc Chi et al., 2013).

\section{Practical application}

Since the beginning of the approach to PTCC techniques, Vietnamese researchers have focused on the practice of producing pure lines, insect-resistant and disease-resistant, and tolerant to adverse environmental factors (salinity, drought) as well as high yield and high quality plant varieties. In particular, PTCC has been widely applied to the rapid propagation of agricultural, forestry, flower and medicinal plant species through stem cutting technique, apical shoot-tip culture, culture of somatic embryos, artificial seeds, etc. Researchers were also interested in the use of PTCC in biomass production to obtain bioactive substances.

\section{Production of double haploid lines through anther culture}

The haploid plants from pollen have great practical significance, because haploid plants are ideal materials to create a pure line. Double haploid lines can be produced by colchicine treatment of haploid plants or through haploid callus tissue culture. Purebred lines are particularly significant in production of hybrids between incompatible parents and shortening the breeding time.

The production of haploid plants through anther culture has been widely used in producing double haploid lines in Vietnam. Double haploid rice (Le Thi Muoi et al., 1978) and tobacco plants (Le Thi Xuan et al., 1978) from in vitro anther culture were the first success of PTCC in Vietnam. These works have laid the foundation for the production of double haploid rice varieties, contributing to 
shortening the time for rice breeding (Bui Ba Bong et al., 1997; Nghiem Nhu Van et al., 2002, 2004; Phan Thi Bay et al., 2004c). The two VH1 and $\mathrm{VH} 2$ rice lines created by the anther culture method have been varietal tested and have gone for trial production (Nghiem Nhu Van et al., 2006). Blast resistant HPMD4, HPMD6, HPMD9, HPMD13, HPMD20 and good quality HPMD4, HPMD9 rice lines have been created by culturing $\mathrm{F} 1$ anthers of a hybrid between quality and blast resistant rice varieties (Phan Thi Bay et al., 2004c). Anther culture was also applied to create pure lines for restoring the quality of specialty Tu Le sticky rice (Dang Thi Minh Lua et al., 2009) (Figure 2).

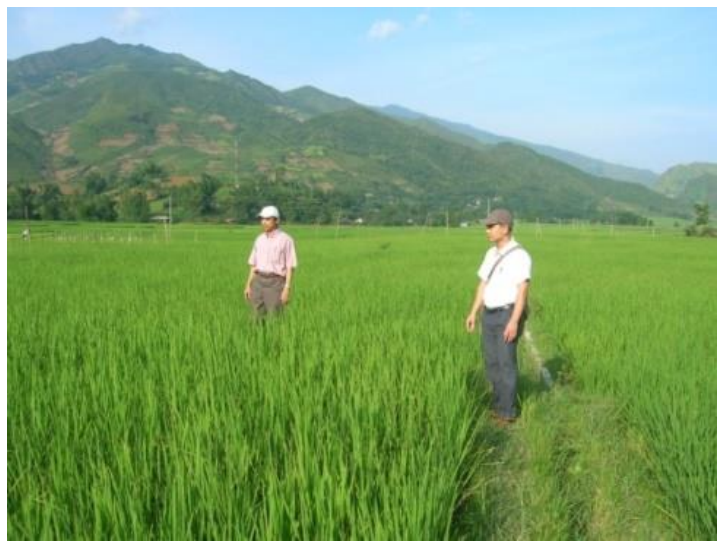

Figure 2. Growing Tu Le sticky rice that was improved by anthers culture in Tu Le commune, Yen Bai Province

Producing disease-resistant potatoes and quality oranges through protoplast fusion

Due to the absence of cellulose wall, protoplasts can be fused to produce somatic hybrids, including nuclear hybrid (Do Thi Thu Ha et al., 2012) and cytoplasmic hybrid (Nguyen Duc Thanh et al., 1996). The use of protoplasts in plant breeding practice has been carried out by the research team of the Institute of Agricultural Biology, University of Agriculture \#1. By fusing protoplasts of the cultivated potato (Solanum tuberosum L. ( $2 \mathrm{n}$ $=4 \mathrm{x}=48)$ and the wild potato species (Solanum bulbocastanum, Solanum tarnii, Solanum pinnatisectum $(2 \mathrm{n}=2 \mathrm{x}=24))$ with the ability resistant to late blight. Related to this, Hoang Thi Giang et al. (2013, 2014) have created a number of late blight resistant potato lines. At the Agricultural Genetics Institute, in order to improve the quality of orange varieties, Ha Thi Thuy et al. (2010) fused protoplasts between the local orange variety (Citrus nobilis) and sweet orange varieties $(C$. sinensis).

\section{Producing plants resistant to salinity, drought and pests through selection of cell lines}

Selection of plant cell lines is based on heterogeneity of tissues and cells in in vitro culture resulting in somatic variation. In Vietnam, the selection of plant cell lines was applied to select the salinity, drought and disease resistant lines. Nguyen Hoang Loc et al. (1990) selected NaCl-tolerant tobacco lines and drought tolerant sugarcane lines (Nguyen Hoang Loc et al., 2003) through callus culture. Truong Thi Bich Phuong et al. (2002) reported the selection of drought tolerant rice lines by callus culture. Vu Thi Thu Thuy et al. (2013) selected drought tolerant groundnut lines from dehydrated calli. By selecting cell lines from radiation treated calli, Nguyen Thi Huong et al. (2017) have selected a saline tolerant Eucalyptus urophyla callus line that can be regenerated on medium with $125 \mathrm{mM}$ $\mathrm{NaCl}$. Le Thi Bich Thuy et al. (1997) reported the selection of rice lines resistant to fungal pathogen (Piricularia oryzae) and subsequently created rice lines resistant to blast disease (Phan Thi Bay et al., 1997). Rice varieties DR1, DR2 were created by selecting dehydrated calli (Dinh Thi Phong et al., 1999), and DR2 has been recognized as a national variety.

Producing transgenic plants resistant to drought, pests, diseases, and increasing productivity and quality

In addition to the basic research orientation as described above, some laboratories have made efforts to create transgenic plant with drought tolerance (Cao Le Quyen et al., 2009), disease-resistance (Vu Thi Lan et al., 2017), increased productivity 
(Nguyen Duc Thanh et al., 2015) and quality transgenic crops (Tran Thi Luong et al., 2014; Tran Thi Luong, Nguyen Duc Thanh, 2015). However, the results are still modest. MtOsDREB2A (Cao Le Quyen et al., 2009), OsNLI-IF (Nguyen Duy Phuong et al., 2015) and OsNACl (Pham Thu Hang et al., 2016) control drought tolerance were transferred to rice and NF-YB2 (Nguyen Van Dong et al., 2015) gene was transferred to maize to creating drought tolerant lines. The gene coding glycine-betaine was transferred to Melia azedarach L. to create salt tolerant plants (Chu Hoang Ha, Bui Van Thang, 2017). Herbicide resistant (Pham Thi Ly Thu et al., 2015) and insect resistant maize (Pham Thi Ly Thu et al., 2013), insect resistant soybean (Nguyen Van Dong, 2012) were created by transferring $G A 21$, cryAl, crylb genes into maize and soybean. Tran Thi Cuc Hoa et al. (2017) used the new vector pHOA60, pH0A100, pH0A130 to transfer VIP3A gene into soybean to create plants resistant to fruit flies. Transgenic tobacco plants resistant to two mosaic viruses were created by RNAi transformation (Pham Thi Van et al., 2009). Also by RNAi transfer method, Nguyen Thi Hai Yen et al. (2011) created a line of transgenic tomato PT18 resistant to viral leaf curl disease. Vu Thi Lan et al. (2018) transferred the cry3CAl gene to sweet potato to create sweet potato lines resistant to the Cylas formicarius. Vi Thi Xuan Thuy et al. $(2016,2017)$ reported the transformation of the DEFENCIN (ZmDEF1) gene from the local maize resistant to the weevil to the elite maize variety to create elite maize lines resistant to weevil.

Shrunken 2 (Sh2) (Tran Thi Luong et al., 2014) and Brittle 2 (Bt2) genes (Nguyen Thi Thu et al., 2014; Nguyen et al., 2016) encoding ADP-glucose pyrophosphorylase-an enzyme that regulates starch synthesis, were successfully transferred into maize and transgenic maize that increase starch content from 10.12 to $16.04 \%$ and yield over 5 tons/ha were obtained. As maize is a low-quality food crop (lack of lysine, tryptophan, low provitamin A including $\alpha$-carotene, $\beta$-carotene and $\beta$-cryptoxanthin), with the aim of improving the quality of maize, Tran et al. (2017) had transferred the IbOr gene from the Hoang Long sweet potato variety into several maize lines and created transgenic maize plants with increased $\beta$-carotene content more than 10 fold, contributing to improving the nutritional quality of maize (Tran et al., 2017; Tran Thi Luong \& Nguyen Duc Thanh, 2018). Tran Thi Xuan Mai \& Tran Thi Cuc Hoa (2017) reported the production of transgenic rice plants with lysine content increased up to $38 \%$ by transferring DHDPS-rl gene encoding the dihydrodipicolinate synthase (DHDPS) enzyme into the Taipei 309 rice variety.

\section{Rapid propagation, conservation and development of genetic resources}

In vitro propagation, in vitro micropropagation, or simply micropropagation has the advantage of having a high multiplication coefficient, the ability to multiply large numbers of plants in a small area. Disease-free plants and no contact with disease sources should ensure seedlings are free of diseases. In addition, micropropagation makes it easy to exchange and transport the seedlings. Therefore, micropropagation has been widely applied in plant breeding, conservation and development of rare genetic resources. During the 45 years of PTCC development in Vietnam, perhaps the most important contribution is the in vitro propagation of agricultural, forestry, floral and medicinal plants, including some endangered plants.

\section{Agricultural plants}

Among the micropropagated agricultural plants, potato was the first and obtained impressive results. Nguyen Van Uyen had successfully implemented in vitro propagation of potato in Da Lat at the family laboratories and produced potato seedlings in pots by using potato seedbed method. In addition to propagating potato by cutting in vitro stems, propagation through producing minitubers from in vitro seedlings has also been conducted successfully (Nguyen Quang Thach et al., 2005). 
After potato, banana ( $\mathrm{Vu}$ Ngoc Phuong et al., 2009; Do Dang Giap et al., 2012b), pineapple (Phan Thi Bay et al., 1994a; Nguyen Duc Thanh et al., 2003), sugarcane (Ha Thi Thuy et al., 1998; Nguyen Kim Lan et al., 1998) have been propagated in vitro and provided millions of qualified and disease-free seedlings for breeding. The Institute of Tropical Biology, the Institute of Biotechnology, the Agricultural Genetics Institute, the Vegetable Research Institute, the Agricultural University $\# 1$ are the places that have propagated bananas, especially Cavendish species in the large scale. Vu Ngoc Phuong et al., (2009) reported about in vitro propagation of banana (Cavendish $\mathrm{sp}$.) on an industrial scale.

The Cayenne pineapple propagation protocol has been developed by the Institute of Biotechnology in cooperation with the Institute of Fruit and Vegetable Research and was transferred to seedling production to supply pineapple seedlings for farms (Nguyen Duc Thanh et al., 2003) (Figure 3).

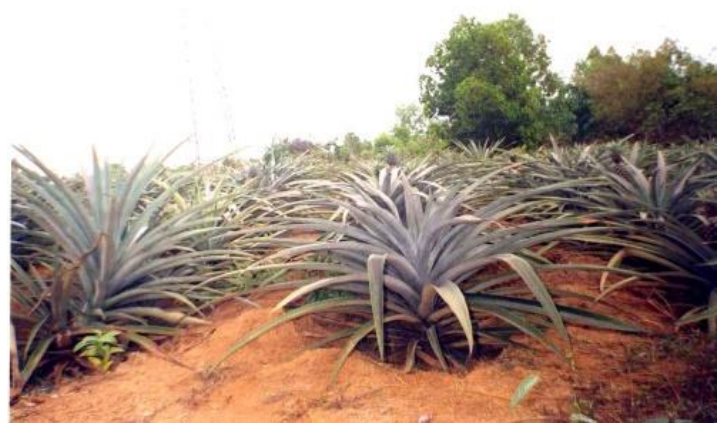

Figure 3. In vitro propagated Cayene pineapple grown at Suoi Hai Farm (in 2000)

In vitro propagation of sugarcane has been carried out methodically at the Institute of Agricultural Genetics, especially the development and propagation of new and high yielding sugarcane at the industrial scale ( $\mathrm{Ha}$ Thi Thuy et al., 1998, 1999., 2000a, 2000b).

\section{Flower}

Micropropagation has made a significant contribution to the propagation of flowering plants, especially orchids. PTCC laboratories throughout the North, Central and South have studied and propagated these precious flowers. Tay Nguyen Institute of Biology (current Tay Nguyen Scientific Research Institute) propagates Cymbidium sp. (Phan Xuan Huyen et al., 2004), Paphiopedilum callosum (Vu Quoc Luan et al., 2012, 2013b), Paphiopedilum graxtrixianum (Vu Quoc Luan et al., 2013a), and Dendrobium heterocarpum Lindl (Dang Thi Tham et al., 2018). The Institute of Tropical Biology propagated Dendrobium sp., Phalaenopsis sp., Cymbidium sp. and Rhynchostylis sp. (Mai Thi Phuong Hoa et al., 2011; Bui Thi Tuong Thu, Tran Van Minh, 2011). The number of orchids like Phalaenopsis Sogo Yukidian (Nguyen Thi Son et al., 2014), Dendrobium fimbriatum, Dendrobium nobile L. (Nguyen Thi Son et al., 2012a, 2012b; Vu Ngoc Lan \& Nguyen Thi Ly Anh, 2013), Cymbidium sp. (Nguyen Quang Thach et al., 2004), Cymbidium iridioides (Hoang Thi Nga et al., 2008, and Paphiopedilum hangianum Perner $\&$ Gruss (Hoang Thi Giang et al., 2010) were successfully propagated in the Institute of Agricultural Biology. Pham Thi Kim Hanh et al. (2009) in the Agriculture Genetics Institute reported the propagation of Rhynchostylis gigantean orchid. Other orchids such as Dendrobium anosmum (Nguyen Quynh Trang et al., 2013), Dendrobium crepidatum Lindl. \& Paxt (Nguyen Van Ket \& Nguyen Van Minh, 2010), and Dalybium gratiosisstimum Reichenb F. (Vu Kim Dung et al., 2016), have also been propagated through micropropagation.

In addition to orchids, in vitro propagation of many other flowering plants have been studied e.g. Lilium longiflorum (Nguyen Thi Phuong Thao \& Nguyen Quang Thach, 2005; Nguyen Thi Phuong Thao et al., 2006; Doan Thi Quynh Huong et al., 2013), Lilium spp. (Nguyen Thi Ly Anh et al., 2005; Do Minh Phu et al., 2009), Polianthes tuberosa (Duong Tan Nhut, 1994), carnation (Nghiem Ngoc Minh, 1992), roses (Phan Thi Bay et al., 1996; Nguyen Thi Kim Thanh, 2005; Nguyen Thi 
Phuong Thao et al., 2015, Nguyen Van Viet, 2017), Chrysanthemums (Nguyen Thi Dieu Huong \& Duong Tan Nhut, 2004), Anthurium andraeanum (Hoang Thi Nhu Phuong et al., 2014; Nguyen Thi Thuy Diem, 2015), and Hydrangea macrophylla (Thi The Luc et al., 2017) have been successfully propagated.

Forest trees

Among forestry trees, acacia has been the most widely and successfully used for in vitro propagation. Particularly, hybrid Acacia, Acacia crassicarpa A. Cunn. Ex Benth, and Acacia auriculiformis A. Cunn. Ex Banth (Doan Thi Mai et al., 1998, 2009b; Phi Hong Hai \& Van Thu Huyen, 2016; Trieu Thi Thu Ha et al., 2014). Eucalyptus varieties (Le Kim Dao, 2001) have been widely propagated to provide seedling sources for reforestation. Besides, other species such as Melaleuca (Phung Thi Hang \& Nguyen Bao Toan, 2011), Caribaea pine (Kieu Phuong Nam et al., 2009), resin pinePinus merkusii (Do Tien Phat et al., 2009; Pham Thi My Lan, Nguyen Xuan Cuong, 2014), Paulownia fortunei (Nguyen Thi Quynh et al., 2002; Doan Thi Ai Thuyen et al., 2001), Aquilaria crassma Pierre (Nguyen Hoang Loc et al., 1997), Chukrasia tabularis (Doan Thi Mai et al., 2009a), Aquilaria crassna Pierre (Le Van Thanh \& Nguyen Thi Hien, 2010), Azadirachta indica A. Juss (Vu Ngoc Phuong et al., 2000) Sinocalamus latiflorus and Dendrocalamus asper ( $\mathrm{Vu}$ Ngoc Phuong et al., 2002) were also propagated by the micropropagation method.

\section{Medicinal plants}

For medicinal plants, many species have been cultivated and propagated in vitro. However, the results are still very modest. The plant species that have been studied and propagated include Crinum latifolium, Polyscias fruticosa, Morinda officinalis, Anoectochilus setaceus Blume, Dendrobium officinale Kimura et Migo, and ginseng species.

Quach Thi Lien et al. (2003) studied regeneration of Crinum latifolium plants. Polyscias fruticosa was most studied for in vitro propagation (Nguyen Ngoc Dung, Nguyen Van Uyen, 1997; Vu Hoai Sam \& Pham Van Hien, 2005; Le Nhu Thao et al., 2014; Dao Duy Hung et al., 2017; Trinh Viet $\mathrm{Nga}$ et al., 2019). Orchid species with high pharmaceutical value such as Anoectochilus setaceus Blume or Anoectochilus roxburghii (Wall.) Lindl. (Nguyen Quang Thach \& Phi Thi Cam Mien, 2012; Truong Thi Bich Phuong \& Phan Ngoc Khoa, 2013; Vu Quoc Luan et al., 2015; Tran Thi Hong Thuy et al., 2015; Phan Xuan Huyen et al., 2018), Dendrobium officinale Kimura et Migo (Trinh Thi Thuy An \& Nguyen Thi Tam, 2017; Le Thi Diem \& Vo Thi Bach Mai, 2017) have been, successfully, in vitro propagated. Other medicinal plants like Codonopsis javanica Blume (Phan Xuan Huyen et al., 2014; Doan Trong Duc et al., 2015), Milletia speciora Champ (Ta Nhu Thuc Anh et al., 2014), Celastrus hindsii (Ta Nhu Thuc Anh \& Nguyen Thi Bich Thu, 2012), Artemisia annua (Mai Thi Phuong Hoa et al., 2012; Bui Thi Tuong Thu et al., 2012), Japanese Angelica acutiloba Kitagawa (Hoang Ngoc Nhung \& Nguyen Thi Quynh, 2015), Lavandula angustifolia (Do Tien Vinh et al., 2016), Rehmannia glutinosa (Vu Hoai Sam et al., 2018), and Polygonum multiflorum (Truong Thi Bich Phuong et al., 2008; Bui Van Thang, 2017) have also been propagated in vitro. Ginseng, in particular, Ngoc Linh ginseng (Figure 4) have received much attention for in vitro propagation. Ngoc Linh ginseng (Panax vietmamensis $\mathrm{Ha}$ et Grushv) has been propagated through somatic embryos from leaves, petioles or stems (Mai Truong et al., 2013; Vu Thi Hien et al., 2014), by artificial seeds (Tran Thi Huong \& Duong Tan Nhut, 2011 ) or in vitro root generation (Hoang Xuan Chien et al., 2011). In addition, other ginseng species such as Lai Chau ginseng - Panax vietnamensis var fuscidiscus (Le Hung Linh \& Dinh Xuan Tu, 2017), Hibiscus sagittifolius Kurz (Phan Duy Hiep et al., 2014) and Milletia speciora Champ (Ta Nhu Thuc Anh et al., 2014) have also been studied for in vitro propagation. 


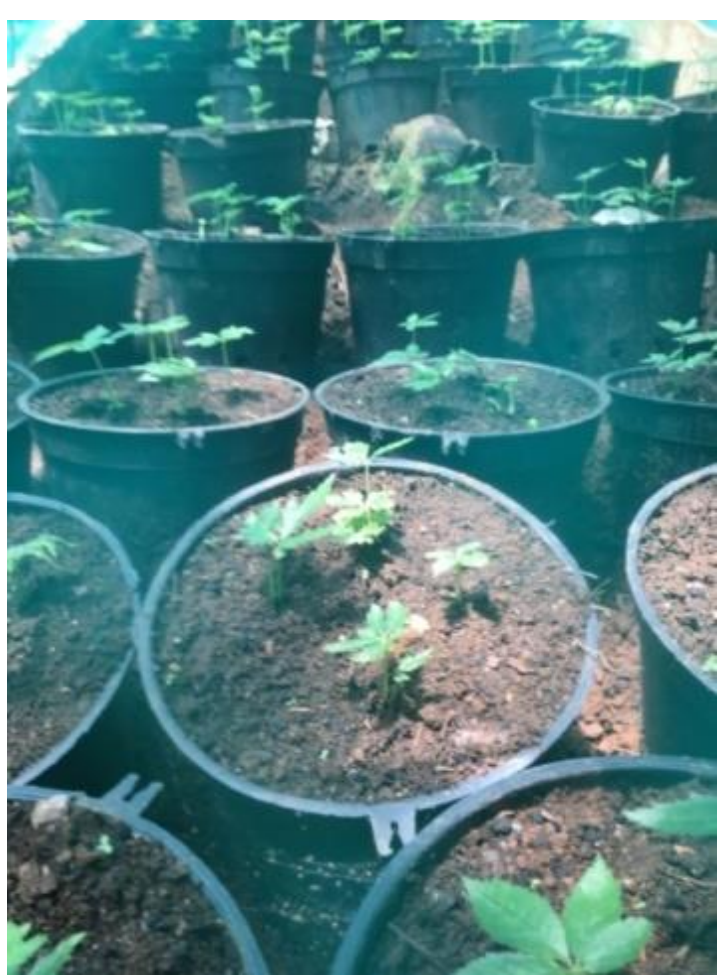

Figure 4. Ngoc Linh Ginseng propagates in vitro at the National Center for Research and Development of Ngoc Linh Ginseng grown in pots on Ngoc Linh Mountain

\section{Endangered plants}

PTCC also contributes significantly to the conservation and development of rare and precious gene sources, especially endangered species. In Vietnam, PTCC has been applied to the conservation and development of a number of rare and endangered plants such as endangered orchid species, Lyptostrobus pensilis (Staunton ex D. Don) K. Koch, and Huperzia serrata Thunb.

Among the orchids, Anoectochilus setaceus, Dendrobium chrysotoxum, Dendrobium heterocarpum and Dendrobium draconis are the precious species that have both aesthetic and medicinal value. However, these orchids are in danger of extinction. Anoectochilus setaveus Blume has been studied for conservation by restricted growth culture (Nguyen Quang Thach \& Phi Thi Cam Mien, 2012; Vu Hoai Sam et al., 2016) and in vitro micropropagation through protocormlike bodies (Tran Thi Hong Thuy et al., 2015). Dendrobium chrysotoxum - an endangered wild orchid species (Nguyen Van Song et al., 2011) and Dendrobium heterocarpum lindl (Dang Thi Tham et al., 2018) have been studied to multiply in vitro for gene conservation and development.

Lyptostrobus pensilis (Staunton ex D. Don) K. Koch is not only an endangered gene source but also a precious medicinal plant, from which some substances can be extracted from the bark and leaves to prepare pharmaceuticals for cancer treatment. The wood is reddish-brown with beautiful wood grain, very solid, free from wood weevil, so that it is very popular and has high value. This species has been successfully propagated in vitro by a research team at Da Lat University (Nguyen Thanh Sum et al., 2007) and the Institute of Biotechnology, Vietnam Academy of Science and Technology (Nguyen Duc Thanh et al., 2012).

Huperzia serrata Thunb is a species in the RED list of the Research Program for conservation and development of precious and rare gene sources of medicinal plants. The plant contains an alkaloid called huperzine, which is effective in curing dementia, including Alzheimer's disease of the elderly. Recently Huperzia serrata Thunb has been successfully studied in vitro propagation for the purpose of conservation and development (Phan Xuan Binh Minh et al., 2019).

Application of PTCC has also been conducted for the conservation and rapid multiplication of other medicinal plants, especially rare, economically valuable, highyield and high quality species such as: Morinda officinalis How., Dendrobium nobile Lindl., Saussurea lappa CB Clarke, Fallopia multiflora (Thunb). Haraldson), Ligusticum wallichii Franch, Salvia miltiorrhiza Bunge, and Lilium brownii F.E.Br. Ex Miellez (Nguyen Minh Khoi et al., 2017). 


\section{Photoautotrophic micropropagation}

Photoautotrophic micropropagation, also known as photosynthesis micropropagation, inorganic micropropagation, and sugar-free medium micropropagation (Kozai et al., 2005) has been applied by Vietnam plant tissue culturists to culture different plant species. Photoautotrophic micropropagation has many advantages related to improvement of the physiology of seedlings and management during production, and it helps to reduce production costs as well as improve the quality of seedlings. Photoautotrophic micropropagation has been performed in both herbaceous and woody plants. This method has brought a breakthrough in large-scale production of disease-free, genetically homogeneous plants with the ability to outgrow and grow better than normal micropropagation and, therefore, can make a big contribution to the research and production of seedling. In Vietnam, photoautotrophic micropropagation was initiated in 1996 by Nguyen Van Uyen of the Institute of Tropical Biology and has been implemented by his colleagues Nguyen Thi Quynh, Nguyen Tri Minh and Thai Xuan Du since 1997 till now. Photoautotrophic micropropagation was developed in conjunction with the development of in vitro environmental control techniques such as $\mathrm{CO}_{2}$ concentration, light, photosynthetic flux, relative humidity, and airflow rates in flasks. These are important environmental factors that affect the growth and development of seedlings. Pham Minh Duy et al. (2014) studied the growth and secondary compound accumulation of Phyllanthus amarus (Schum. $\&$ Thonn.) cultured photoautotrophically under a $\mathrm{CO}_{2}$-rich environment. The factors such as light, air permeability, humidity were also studied (Nguyen et al., 2001; Nguyen Thi Quynh et al., 2010a, 2010b; Nguyen Nhu Hien et al., 2009; Nguyen Nhu Hien \& Nguyen Thi Quynh, 2010). Photoautotrophic culture for propagation and biomass production was carried out on coffee trees (Nguyen et al., 2001), yam (Dioscorea alata) (Nguyen Thi Quynh et al., 2002; Nguyen \&
Kozai, 2007), orchids (Nguyen Thi Quynh et al., 2010a), Phyllanthus amarus (Schum. \& Thonn.) (Pham Minh Duy et al., 2012, 2014), Ngoc Linh ginseng (Ngo Thi Ngoc Huong et al., 2015), Indian Coleus forskohlii (Nguyen Thuy Phuong Duyen et al., 2015) and Hibiscus sagittifolius Kurz (Nguyen Thuy Phuong Duyen et al., 2017).

\section{Artificial seeds}

Artificial seeds are seed-like structures, created experimentally using somatic embryos derived from plant tissue culture, encapsulated by hydrogels and these encapsulated embryos have the characteristics as true seed when sown, and can be used as a substitute for natural seeds. Use of artificial seeds shortens the seeding time (no need to wait for the plants to grow, flower, set seed), free from seasonal restriction, avoiding seed sleeping, and can be done on a large scale, avoiding meiosis to stabilize the elite genetic resources. The artificial seed coat has the potential to maintain and provide nutrients, growth stimulants and insecticides. In addition, artificial seeds also help to study the role of endosperm and the formation of seed pods.

Researchers in the Tay Nguyen Institute of Biology (currently Tay Nguyen Scientific Research Institute, Vietnam Academy of Science and Technology) were the pioneers in this field. Studies on artificial seeding of Lilium (Duong Tan Nhut et al., 2004b), Cymbidium (Tran Thi Ngoc Lan et al., 2011), and garlic (Do Ngoc Thanh Mai et al., 2015) have been conducted successfully. The preservation (Duong Tan Nhut et al., 2007c) and germination ability (Trinh Thi Huong \& Duong Tan Nhut, 2011; Trinh Thi Huong et al., 2013) of artificial seeds were also studied. Artificial seeds were used for propagation of lilies (Duong Tan Nhut et al., 2004b) orchids (Duong Tan Nhut et al., 2007c; Tran Thi Ngoc Lan et al., 2011), Ngoc Linh ginseng (Trinh Thi Huong \& Duong Tan Nhut, 2011; Trinh Thi Huong et al., 2013) and Codonopsis (Tran Van Thinh et al., 2015). 
Application PTCC for production of secondary biologically active substances

Secondary compounds in plants are those in the plant body but have no role in the basic life process of plants (assimilation, respiration, transport, growth and development) but only play a secondary role. The primary function of secondary compounds is to protect plants against pathogens and herbivores. Many secondary biologically active substances are used as insecticides, fungicides and pharmaceuticals. In plants, the secondary compounds consist of three main groups: terpenoids, phenolic compounds and nitrogencontaining compounds. Many secondary compounds are used as valuable medicinal herbs or food additives.

The development of PTCC has opened up the ability to use this technique to produce biomass capable of synthesizing secondary substances. A large-scale biomass production in laboratories is an alternative to traditional secondary extraction methods from natural plants.

In Vietnam, research on the application of PTCC to acquire secondary substances has been started since the 80 s of the last century on Panax pseudoginseng, Nicotiana, Artemisia аппиa, Taxus wallchiana, etc. Phan Huy Bao \& Le Thi Xuan (1986) generated Panax pseudoginseng plants with high saponin content. The variation of nicotine content in differentiated callus tissues of tobacco was reported by Nguyen Duc Thanh et al. (1991). Tissue culture of Taxus wallchiana was carried out very early by Nguyen Kim Lan et al. (1996) for the purpose of acquiring paclitaxel (Taxol), a substance used to treat certain types of cancer. The acquisition of secondary substances by tissue culture methods is possible through callus culture, cell suspension culture, tuber formation, secondary rooting and hairy root formation. Phan Thi Bay et al. (1994b) cultured callus and regenerated Artemisia annua $\mathrm{L}$. for acquisition of artemisinin, a drug that is effective against malaria. Quach Thi Lien et al. (2005) and Vu Thi Lan et al. (2008) carried out the callus culture of Crinum latifolium L. to obtain saponins and some alkaloids with potential anti-cancer activity. Studies of callus culture to produce biomass to obtain secondary substances have been conducted on a number of other plant species such as: Maesa balansae Mez. (Quach Thi Lien \& Nguyen Duc Thanh, 2004) and Panax vietnamensis Ha et Grushv. (Duong Tan Nhut et al., 2009b). Cultivation of cell suspension has been studied on Artemisia aпnua L. (Bui Thi Tuong Thu et al., 2010), Taxus wallichiana Zucc. (Le Thi Thuy Tien et al., 2006; Duong Tan Nhut et al., 2007d) and Ehretia asperula Zollinger et Moritzi (Tran Thi Tam Hong \& Tran Van Minh, 2019). Panax vietnamensis $\mathrm{Ha}$ et Grushv has received much attention on biomass production, from in vitro tuber production (Hoang Xuan Chien et al., 2011), creating adventitious roots (Duong Tan Nhut et al., 2015a) and secondary roots (Nguyen Thi Nhat Linh et al., 2017, 2018) to hairy root formation (Ha Thi My Ngan et al., 2013; Mai Truong et al., 2013; Pham Bich Ngoc et al., 2013; Tran Thi Ngoc Ha et al., 2013; Trinh Thi Huong et al., 2015; Ha et al., 2016; Ha Thi Loan et al., 2014; Ha Thi Loan \& Duong Hoa Xo, 2017; Ha Thi Thu Hoa et al., 2018). Hairy root culture has also been reported for biomass production to acquire artemisinin from Artemisia annua L. (Bui Thi Tuong Thu et al., 2012) and saponin from Polyscias fruticosa L. Harms (Nguyen Trung Hau et al., 2015).

\section{Contribution to global PTCC}

In addition to the high impact on the development of science and practice in the country, Vietnam PTCC has made impressive contributions to the field of plant tissue and cell culture, in particular, and the world science, in general. Many works implemented in Vietnam have been published in prestigious international journals and monographs. These are studies on factors affecting plant cell tissue culture (Duong Tan Nhut, 2005; Duong Tan Nhut et al., 2005; 2006a; 2007a, 2007b; 2008a, 2015b; 2016; 2017b; Nguyen Hong Vu et al., 2006; Nguyen Ba 
Nam et al., 2016; Vu et al., 2019), on in vitro propagation (Duong Tan Nhut, 1998, 2003; Duong Tan Nhut et al., 2004a, 2009c, 2011), on acquisition of secondary substances from plant tissues and cells (Nguyen Hoang Loc \& Nguyen Thi Tam An, 2010; Nguyen Hoang Loc \& Nguyen Thi Duy Nhat, 2013; Nguyen Hoang Loc et al., 2014, 2017; Nguyen Huu Thuan Anh et al., 2016; Nguyen Thanh Giang et al., 2016; Nguyen Huu Nhan \& Nguyen Hoang Loc, 2017, 2018; Nguyen Thi Nhat Linh et al., 2019), on TCL culture technique (Duong Tan Nhut et al., 2007e, 2012a, 2012b, 2012c, 2013), on gene transfer in plants (Nguyen et al., 2016; Tran et al., 2017; Vi et al, 2017) and on photoautotrophic culture (Nguyen et al., 1999, 2001; Nguyen \& Kozai, 2005; Nguyen et al., 2016, 2020; Hoang et al., 2017). Although these contributions are still modest, it has made a remarkable impression in the world of plant tissue and cell culture.

\section{CHALLENGES AND PROSPECTS}

Over 45 years of establishment and development, Vietnam's PTCC has achieved impressive results. Most PTCC techniques have been applied to basic and practical researches. It can be said that Vietnam's PTCC has developed broadly (broadly in terms of methods, technologies, and research and application facilities). However, the scale is limited. Most of the results are limited to the laboratory scale, some are small and medium pilot, not yet reaching industrial scale. The basic research has not been deeply focused. Although two National Key Laboratories for plant cell technology (one in the Institute of Agricultural Genetics and the other in the Institute of Tropical Biology) and one National Key Laboratory on Genetic Engineering (in the Institute of Biotechnology) have been set-up, but the organization and operating budget still have many problems. The cooperation between research institutions and production enterprises is very limited.

In the future, PTCC will still be an important tool in basic and practical researches. For basic research, especially for cell differentiation, gene expression, antigen production, recombinant protein, and genetically modified plants, these are the areas that will be of great interest. In vitro propagation combined with hydroponic and aeroponic technologies will be a potential approach for rare and high economic value varieties. Industrial-scale cell suspension and hairy root cultures are important approaches to obtain plant-derived secondary substances for pharmaceutical and cosmetic industries.

\section{CONCLUTION}

PTCC was started in Vietnam in the 70s of the last century. The formation and development of Vietnam's PTCC has contributed significantly to the development of plant cell technology, in particular, and biotechnology, in general. Many impressive results have been recorded in basic and practical researches. Many effective in vitro propagation protocols for potato, banana, sugarcane, pineapple, eucalyptus, acacia, etc. have been developed and applied in practice to provide quality seedlings for production. Several techniques such as anther culture, apical shoot-tip culture, thin cell layer culture, and embryos culture have contributed significantly in producing and developing plant varieties (rice, potato, lilies, orchids, Ngoc Linh ginseng, etc.). However, there are some limitations in the use of PTCC to acquire secondary substances, in the studies on gene expression and recombinant protein, and in plant breeding through gene transfer. Along with the impact on domestic science and technology, Vietnam's PTCC has recorded remarkable impressions in the development of this field in the world. These are the researches carried out in Vietnam on culture conditions, TCL culture, and biomass culture for secondary substances acquisition, photoautotrophic micropropagation and gene transfer which have been published in international prestigious journals and monographs.

With high potential for basic and practical research, PTCC have been and will still be an effective tool for the studies on cell proliferation, genetics, biochemistry, improvement and development of plant 
varieties. In order to bring into full potential of PTCC in Vietnam, an attention should be paid to perfecting in vitro propagation procedures that have been properly formulated and appropriately invested in order to expand seedling production on an industrial scale. Combining in vitro propagation with hydroponic and aeroponic is necessary to improve propagation efficiency and produce high quality seedlings. Building and perfecting the protocols of micropropagation, cell suspension culture, embryo culture, hairy root culture for a number of precious and rare medicinal plants of high economic value are critical to obtain secondary substances on an industrial scale. Research on expression of antigen, recombinant protein and on geneedited crops by modern gene editing technology shuld be enhanced. In parallel with technical and technological issues, increasing investment in infrastructure, staff training, promoting linkages between research institute and production enterprises, and timely transfer of completed technologies to the scientific and production enterprises are important solutions for the effective use of PTCC in research and practice.

Acknowledgements: The author would like to thank colleagues who are experts in the field of plant tissue culture for providing useful information so that the review can best reflect the development of plant tissue and cell culture in Vietnam, especially Prof. Dr. Duong Tan Nhut and Prof. Dr. Nguyen Hoang Loc.

\section{REFERENCES}

Bui Ba Bong, Nguyen Duy Bay, Tran Trong Thach, 1997. Results on anther culture of rice. Journal of Biology, 19(3): 31-34. (in Vietnamese with English summary).

Bui Thi Thu Huong, Dong Huy Gioi, Nguyen Thi Trang, Ho Thi Quyen, 2017. Growing Sapa ancient raised (Rosa gallica L.) using in vitro tissue culture technique. Proceeding of $7^{\text {th }}$ National Conference on Ecology and Biological Resources, Hanoi. (in Vietnamese with English summary).

Bui Thi Tuong Thu, Le Thi Hien, Tran Van Minh, 2010. Suspension culture of
Artemisia апnиa L. by bioreactor techniques. Journal of Medicinal Materials, $\quad$ 15(6): 355-358. (in Vietnamese with English summary).

Bui Thi Tuong Thu, Tran Van Minh, 2011. Micropropagation of orchids by somatic embryo culture technique. Journal of Biology, 33(4): 72-78. (in Vietnamese with English summary).

Bui Thi Tuong Thu, Phạm The Anh, Tran Van Minh, 2012. Hair root culture of Artemisia annua $\mathrm{L}$. for artemisinin accumulation by immersion bioreactor technique. Journal of Medicinal Materials, 17(1): 57-62. (in Vietnamese with English summary).

Bui Van Thang, Dinh Thi Phong, Chu Hoang $\mathrm{Ha}, 2004$. An efficient protocol for plant regeneration in peanut (Arachis hypogaea L.) via somatic embryogenesis induction. Journal of Biotechnology, 2(3): 371-379. (in Vietnamese with English summary).

Bui Van Thang, 2017. In vitro propagation of Polygonum multiflorum Thunb.) selected from Ha Giang province. Journal of Forest Science and Technology (University of Forestry), 4: 23-28. (in Vietnamese with English summary).

Cao Le Quyen, Tran Tuan Tu, Phan Xuan Hoi, 2009. Genetic engineering of gene encoding transcription factor MtOsDREB2A form Vietnamese rice variety Chanh trui for drought stress tolerance. Journal of Biology, 31(2): 79-88. (in Vietnamese with English summary).

Cao Le Quyen, Phạm Thi Van, Pham Xuan Hoi, 2011. Study on plant regeneration from embryo of group varieties of Vietnamese upland rice for transformation approach. Journal of Biology, 33(1): 86-95. (in Vietnamese with English summary).

Chu Hoang Ha, Bui Van Thang, 2017. Salinity tolerance of Melia azedarach L. transgenic plants transformed with $\operatorname{cod} A$ gene encoding colin oxidase biosynthesis of glycine-betaine. Journal 
of Agriculture and Rural Development, 18: 163-168. (in Vietnamese with English summary).

Do Dang Giap, Bui Van The Vinh, Nguyen Thi Kim Loan, Thai Xuan Du, Chu Thi Bich Phuong, Hoang Xuan Chien, Nguyen Phuc Huy, Tran Trong Tuan, Nguyen Dinh Lam, Duong Tan Nhut, 2012a. Organogenesis and somatic embryogenesis from leaf transverse thin cell layers of Jatropha curcas L. Journal of Biotechnology, 10(2): 279-288.

Do Dang Giap, Pham Ngoc Vinh, Tran Trong Tuan, Nguyen Thi Huyen Trang, Pham Ngo Anh Thu, Thai Xuan Du, 2012b. High frequency shoot multiplication of Laba banana (Musa sp.) cultured in vitro by using light, myo-inositol and adenine sulphate. Journal of Biology, 34(3SE): 180-187. (in Vietnamese with English summary).

Duong Tan Nhut, 1994. Propagation of lily by pseudo-bulblet culture. Journal of Biology, 16(1): 29-31. (in Vietnamese with English summary).

Duong Tan Nhut, 1998. Micropropagation of lily (Lilium longiflorum) via in vitro stem node and bulb scale culture. Plant Cell Rep., 17(12): 913-916.

Duong Tan Nhut, 2003. The control of in vitro direct main stem formation of Lilium longiflorum derived from receptacle culture, and rapid propagation by using in vitro stem nodes. Plant Grow. Regul., 40(2): 179-184.

Duong Tan Nhut, Nguyen Thi Dieu Huong, Dinh Van Khiem, 2004a. Direct microtuber formation and enhanced growth in the acclimatization of in vitro plantlets of taro (Colocasia esculenta spp.) using hydroponics. Sci. Hortic., 101(1-2): 207-212.

Duong Tan Nhut, Tran Ngoc Thuy Tien, Mai Thi Ngoc Huong, Nguyen Thi Thanh Hien, Phan Xuan Huyen, Bui Van Le, Do Nang Vinh, 2004b. Some results in study on artificial seeds of Lilium spp. Journal of Biotechnology, 2(3): 359-370. (in Vietnamese with English summary).

Duong Tan Nhut, 2005. Positive effects of Bacillus spp. on the growth of Chrysanthemum spp. in vitro and ex vitro. Propag. Ornam. Plants, 5(3): 146-150.

Duong Tan Nhut, Nguyen Duy, Nguyen Nhu Ha Vy, Chau Diem Khue, Dinh Van Khiem, Do Nang Vinh, 2006a. Impact of Anthurium spp. genotype on callus induction derived from leaf explants, and shoots and root regeneration from callus. J. Appl. Hortic., 8(2): 135-137.

Duong Tan Nhut, Nguyen Thi Huyen Tram, Nguyen Thanh Hai, Do Nang Vinh, 2006b. Effects of lily genotype on regenerative ability via young stem transverse thin cell layer and bulb scale culture. Journal of Biotechnology, 4(2): 227-232. (in Vietnamese with English summary).

Duong Tan Nhut, Thai Huu Phu, Phan Xuan Huyen, Dang Thi Thu Thuy, 2007a. Effects of in vitro leaf explants and leaf size on direct shoot regeneration of Gloxinia. Propag. Ornam. Plants, 7(1): 16-22.

Duong Tan Nhut, Truong Thi Thuy An, Nguyen Thi Dieu Huong, Nguyen Trinh Don, Nguyen Thanh Hai, Nguyen Quoc Thien, Nguyen Hong Vu, 2007b. Effect of genotype, explant size, position, and culture medium on shoot generation of Gerbera jamesonii by receptacle transverse thin cell layer culture. Sci. Hortic., 111(2): 146-151.

Duong Tan Nhut, Nguyen Thi Kim Tuyen, Nguyen Duy, Mai Xuan Phan, 2007c. Regeneration and storage of Phalaenopis artificial seeds. Journal of Biotechnology, 5(1): 85-95. (in Vietnamese with English summary).

Duong Tan Nhut, Nguyen Trinh Don, Nguyen Thi Thanh Hien, Dinh Van Khiem, Le Thi Xuan, 2007d. Cell culture and callus recovery from suspension of Himalayan yew (Taxus wallichiana Zucc.). Journal of Biotechnology, 5(2): 205-215. 
Duong Tan Nhut, Bui Le Thanh Khiet, Nguyen Ngoc Thi, Dang Thi Thu Thuy, Nguyen Duy, Nguyen Thanh Hai, Phan Xuan Huyen, 2007e. High frequency shoots formation of yellow passion fruit (Passiflora edulis f. flavicarpa) via thin cell layer (TCL) technology. In: Mohan Jain S., Häggman H. (eds.), Protocols for micropropagation of woods trees and fruits. Springer, Germany, pp. 417-426.

Duong Tan Nhut, Nguyen Ngoc Thi, Bui Le Thanh Khiet, $\mathrm{Vu}$ Quoc Luan, 2008a. Peptone stimulate in vitro shoot and root regeneration of avocado (Persea americana Mill.). Sci. Hortic., 115(2): 124-128.

Duong Tan Nhut, Phan Dinh Kim Thu, Truong Thi Dieu Hien, Trinh Thi Lan Anh, Nguyen Ba Nam, Phan Quoc Tam, Bui The Giang, Vo Hoang Thuy An, Vo Quoc Bao, 2008b. Somatic embryogenesis of the Lilium cultivar "Oriental "Alma Ata" via the bulb scale transverse thin cell layer culture. Journal of Biotechnology, 6(4): 475-482. (in Vietnamese with English summary).

Duong Tan Nhut, Bui Van The Vinh, 2009. Effects of plant growth regulators on the morphogenesis of cauliflower curd transverse thin cell layer explants. Journal of Biotechnology, 7(2): 229-233.

Duong Tan Nhut, Nguyen Ba Nam, 2009. The effect of light-emitting diode (LED) system on growth and development of Chrysanthemum moriflorum cv. "Nut" plantlets in vitro. Journal of Biotechnology, 7(1): 93-100. (in Vietnamese with English summary).

Duong Tan Nhut, Hong Ngoc Tram, Nguyen Phuc Duy, Dinh Van Khiem, 2009a. Influences of the coconut water and sucrose on the embryogenic callus induction and the clonal embryo formation of Phalaenopsis amabilis (L.) Blume. Journal of Biology, 31(1): 77-84. (in Vietnamese with English summary).

Duong Tan Nhut, Vu Quoc Luan, Nguyen Van Binh, Pham Thanh Phong, Bui Ngoc Huy, Dang Thi Ngoc Ha, Phan Quoc Tam,
Nguyen Ba Nam, Vu Thi Hien, Bui The Vinh, Lam Thi My Hang, Duong Thi Mong Ngoc, Lam Bich Thao, Tran Cong Luan, 2009b. The effects of some factors on in vitro biomass production of Vietnamese ginseng (Panax vietnamensis Ha et Grushv.) and preliminary analysis of saponin content. Journal of Biotechnology, 7(3): 357-370.

Duong Tan Nhut, Nguyen Thanh Hai, Mai Xuan Phan, 2009c. A highly efficient protocol for micropropagation of Begonia tuberous. In: Mohan Jain S., Ochattt Sergio J. (eds.), Protocols for in vitro propagation of ornamental plants. Springer, USA, pp. 1-13.

Duong Tan Nhut, Nguyen Phuc Huy, Vu Quoc Luan, Nguyen Van Binh, Nguyen Ba Nam, Le Nu Minh Thuy, Dang Thi Ngoc Ha, Hoang Xuan Chien, Trinh Thi Huong, Hoang Van Cuong, Le Kim Cuong, Vu Thi Hien, 2011. Shoot regeneration and micropropagation of Panax vietnamensis $\mathrm{Ha}$ et Grushv. from ex vitro leaf-derived callus. Afr. $J$. Biotechnol., 10(84): 19499-19504.

Duong Tan Nhut, Bui Van The Vinh, Thai Thuong Hien, Nguyen Phuc Huy, Nguyen Ba Nam, Hoang Xuan Chien, 2012a. Effects of spermidine, proline and carbohydrate sources on somatic embryogenesis from main root transverse thin cell layers of Vietnamese ginseng (Panax vietnamensis Ha et Grushv.). Afr. J. Biotechnol., 11(5): 1084-1091.

Duong Tan Nhut, Hoang Tran Minh Thu, Bui Van The Vinh, Nguyen Van Binh, Vu Quoc Luan, 2012b. Thin cell layer technology in regeneration and micropropagation of Cyclamen persicum Mill. Propag. Ornam. Plants, 12(2): 89-95.

Duong Tan Nhut, Nguyen Phuc Huy, Hoang Xuan Chien, Tran Cong Luan, Bui The Vinh, Lam Bich Thao, 2012c. In vitro culture of petiole longitudinal thin cell layer explants of Vietnamese ginseng (Panax vietnamensis $\mathrm{Ha}$ et Grushv.) and preliminary analysis of saponin content. 
Inter. J. Appl. Biol. Pharm. Technol., 3(3): 178-190.

Duong Tan Nhut, Do Dang Giap, Bui Van The Vinh, Nguyen Thi Kim Loan, Nguyen Phuc Huy, Nguyen Thanh Hai, Hoang Xuan Chien, Tran Trong Tuan, Thai Xuan $\mathrm{Du}, 2013$. Thin cell layer technology in regeneration and micropropagation of Jatropha curcas L. In: Jain S. M., Dutta Gupta S. (eds.), Biotechnology of neglected and underutilized crops. Springer, pp. 33-42.

Duong Tan Nhut, Tran Hieu, Nguyen Thi Nhat Linh, Hoang Thanh Tung, Nguyen Ba Nam, Nguyen Phuc Huy, Vu Quoc Luan, Vu Thi Hien, 2015a. Optimum conditions for proliferation and saponin accumulation of Panax vietnamensis $\mathrm{Ha}$ et Grushv. adventitious roots in culture systems. Journal of Biotechnology, 13(3): 853-864. (in Vietnamese with English summary).

Duong Tan Nhut, Nguyen Phuc Huy, Ngo Thanh Tai, Nguyen Ba Nam, Vu Quoc Luan, Vu Thi Hien, Hoang Thanh Tung, Bui The Vinh, Tran Cong Luan, 2015b. Light-emitting diodes and their potential in callus growth, plantlet development and saponin accumulation during somatic embryogenesis of Panax vietnamensis $\mathrm{Ha}$ et Grushv. Biotechnol. Biotec. EQ., 29(2): 299-308.

Duong Tan Nhut, Hoang Thanh Tung, Luong Thien Nghia, Nguyen Duy Anh, Nguyen Phuc Huy, Nguyen Ba Nam, Vu Quoc Luan, Vu Thi Hien, 2017a. Sterilizing medium using silver nanoparticles in micropropagation of Chrysanthemum morifolium Ramat cv. Jimba. Journal of Biotechnology, 15(3): 505-513. (in Vietnamese with English summary).

Duong Tan Nhut, Nguyen Phuc Huy, Hoang Thanh Tung, Vu Quoc Luan, Nguyen Ba Nam, 2017b. LEDs and their potential in somatic embryogenesis of Panax vietnamensis $\mathrm{Ha}$ et Grushv. In: Light emitting diodes for agriculture-Smart lighting, S. Dutta Gupta (Ed.), Springer, pp. 321-330.

Dao Duy Hung, Le Thi Hao, Nguyen Thi Huong Xiem, Ngo Xuan Binh, Nguyen Sinh Huynh, 2017. In vitro propagation of Polyscias fruticosa L. Harms. Journal of Agriculture and Rural Development, 8: 4652. (in Vietnamese with English summary).

Dao Thi Sen, Nguyen Chi Mai, Le Quynh Lien, Tran My Linh, Chu Hoang Ha, Nguyen Tuong Van, 2016. Vector construction to enhance GP5 antigen expression of virus PRRS in plant cells. Journal of Biotechnology, 14(3): 491-497. (in Vietnamese with English summary).

Dang Thi Minh Lua, Le Thi Bich Thuy, Nguyen Duc Thanh, 2009. Anther culture for production of homogenous lines in the Tu Le traditional glutinous rice. Journal of Biotechnology, 7(1): 47-52. (in Vietnamese with English summary).

Dang Thi Tham, H'Yon Nie Bing, Nguyen Thi Thanh Hang, Dinh Van Khiem, Nong Van Duy, Tran Thai Vinh, Quach Van Hoi, Vu Kim Cong, 2018. Micropropagation of Dendrobium heterocarpum lindl. Journal of Biotechnology, 16(1): 127-135. (in Vietnamese with English summary).

Dinh Thi Phong, Nguyen Hoang Tinh, Chu Hoang Ha, Le Tran Binh, Le Thi Muoi, 1999. Results on selection of two new rice varieties DR1, DR2 by plant cell biotechnology. Journal of Science and Technology, 36(4): 6-14. (in Vietnamese with English summary).

Do Minh Phu, Doan Thi Thuy Van, Dang Van Dong, Trinh Khac Quang, 2009. Study on improvement of protocol for propagation of lily by in vitro culture method. Journal of Vietnam Agricultural Science and Technology, 3: 21-26. (in Vietnamese with English summary).

Do Nang Vinh, 1979. Production of rice plants from in vitro anther culture of $\mathrm{F} 1$ hybrids and following their progenies. Journal of Biology, 1(3): 16-22. (in Vietnamese with English summary). 
Do Ngoc Thanh Mai, Pham Thi Ngoc Tu, Pham Thi Phuong Thao, To Thi Nha Tram, Hoang Thanh Tung, Hoang Van Cuong, Hoang Xuan Chien, Duong Tan Nhut, 2015. Artificial seed from somatic embryos formed from in vitro cultured root tips of garlic (Allium sativum L.). Journal of Biotechnology, 13(2A): 493-499. (in Vietnamese with English summary).

Do Thi Gam, Chu Hoang Ha, Pham Bich Ngoc, Nguyen Khac Hung, Phan Hong Khoi, Ha Thi Thanh Binh, Nguyen Nhu Chuong, Luong Tu Nam, Nguyen Thi Thuy Binh, 2017. Effect of LED light on in vitro growth and development of Anoectochilus roxburghi. Journal of Biotechnology, 15(1): 97-104. (in Vietnamese with English summary).

Do Thi Thu Ha, Nguyen Thi Thuy, Vu Thi Hang, Hoang Thi Giang, Nguyen Thi Phuong Thao, Nguyen Quang Thach, Ramona Thieme, Andrea Schwarzfischer, 2012. A study on identification of potato somatic hybrids from regenerative after protoplast fusion. Journal of Agriculture and Rural Development, 10: 16-25. (in Vietnamese with English summary).

Do Tien Phat, Nguyen Chi Mai, Dang Hoa Hieu, Le Van Son, Chu Hoang Ha, Le Tran Binh, 2007. An efficient protocol for plant regeneration in "cam Sanh" (Citrus nobilis Loureiro) via multi-shoot induction from epicotyl segments. Journal of Biotechnology, 5(3): 363-370. (in Vietnamese with English summary).

Do Tien Phat, Dinh Thi Phong, Nguyen Van Phuong, Chu Hoang Ha, Vuong Dinh Tuan, 2009. Plant regeneration from mature seed's embryo of Pinus merkusii. Journal of Biotechnology, 7(1): 59-65. (in Vietnamese with English summary).

Do Tien Vinh, Mai Thi Phuong Hoa, Le Bao Ngoc, Tran Van Minh, 2016. In vitro propagation of Lavandula angustifolia. Journal of Medicinal Materials, 21(4): 279-284. (in Vietnamese with English summary).
Do Xuan Dong, Chu Hoang Ha, Le Tran Binh, 2007. Study on plant regeneration and transformation system of some Vietnamese tomato cultivars (Lycopersicon esculentum Mill.). Journal of Biotechnology, 5(2): 217-223. (in Vietnamese with English summary).

Do Xuan Dong, Bui Van Thang, Ho Van Giang, Nong Van Hai, Chu Hoang Ha, 2008. An efficient protocol for plant regeneration of xoan tree (Melia azedarach L.) via somatic embryogenesis induction. Journal of Biotechnology, 6(2): 227-232. (in Vietnamese with English summary).

Doan Thi Ai Thuyen, Vu Ngoc Phuong, Thai Xuan Du, Nguyen Van Uyen, 2001. Propagation of Paulownia fortune (Seem.) Hermsl. By tissue culture method. Journal of Biology, 23(3): 46-50. (in Vietnamese with English summary).

Doan Thi Mai, Tran Ho Quang, Ngo Thi Minh Duyen, 1998. A technique for propagation of Acacia using meristem culture. Vietnam Journal of Forest Science 7: 35-36 (in Vietnamese with English summary).

Doan Thi Mai, Nguyen Thi My Huong, Van Thu Huyen, Vu Thi Ngoc, Tran Thanh Huong, 2009a. Propagation of Lat hoa (Chukrasia tabularis) by tissue culture method. Vietnam Journal of Forest Science, 4: 1-7. (in Vietnamese with English summary).

Doan Thi Mai, Nguyen Thi My Huong, Vu Thi Ngoc, Tran Thanh Huong, Van Thu Huyen, 2009b. Tissue culture same new selected Acacia. Vietnam Journal of Forest Science, 2: 1-6. (in Vietnamese with English summary).

Doan Thi Quynh Huong, Trinh Thi Huong, Nguyen Phuc Huy, Duong Tan Nhut, 2013. Micropropagation of Calla lily (Zantedeschia sp.) via shoot tip culture. Journal of Biotechnology, 11(3): 513-519. (in Vietnamese with English summary). 
Doan Trong Duc, Tran Van Minh, 2015. Cloning of Vietnam Dang Sam (Codonopsis javanica (Blume) Hook. f. et Thoms.) in vitro. Journal of Medicinal Materials, 20(1): 50-56. (in Vietnamese with English summary).

Ha Thi Loan, Duong Hoa Xo, Nguyen Quoc Binh, Nguyen Hoang Quan, Vu Thi Dao, Nathalie Pawlicki-Jullian, Eric Gontier, 2014. Study on obtaining of hairy root of Panax vietnamensis by using rol gene transformation via Agrobacterium rhizogenes. Journal of Biology, 36(1se): 293-300. (in Vietnamese with English summary).

Ha T. L., Pawlicki-Jullian N., Pillon-Lequart M., Boitel-Conti M., Duong H. X., Gontier E., 2016. Hairy root cultures of Panax vietnamensis, a promising approach for the production of ocotillol-type ginsenosides. Plant Cell Tiss. Org., 126: 93-103.

Ha Thi Loan, Duong Hoa Xo, 2017. Effect of culture conditions on the rapid multiplication of Ngoc Linh ginseng hair root biomass on Plantima system. Journal of Vietnam Agricultural Science and Technology, 6(79): 45-49. (in Vietnamese with English summary).

Ha Thi My Ngan, Trinh Thi Huong, Nguyen Ba Nam, Le Kim Cuong, Nguyen Phuc Huy, Vu Thi Hien, Vu Quoc Luan, Nguyen Hong Hoang, Ngo Thanh Tai, Nguyen Dinh Trong, Pham Bich Ngoc, Chu Hoang Ha, Duong Tan Nhut, 2013. Agrobacterium rhizogenes-mediated hairy roots formation of $\mathrm{Ngoc}$ Linh ginseng (Panax vietnamensis $\mathrm{Ha}$ et Grushv.) Journal of Biotechnology, 11(3): 479-486. (in Vietnamese with English summary).

Ha Thi Thu Hoa, Nguyen Bach Dang, Ha Thi Loan, 2018. Studying rapidly multiplying Ngoc Linh ginseng hair roots on bioreactor system and economic efficiency when manufacturing in the laboratory. Journal of Science and Technology of Agriculture and
Forestry, 2: 33-42. (in Vietnamese with English summary).

Ha Thi Thuy, Le Huy Ham, Do Nang Vinh, 1998. Rapid multiplication of high yielding sugarcane varieties by micropropagation technology. Journal of Agriculture and Food Technology, 2: 72-73. (in Vietnamese with English summary).

Ha Thi Thuy, Le Huy Ham, Do Nang Vinh, 2000a. Study on improving the root induction of in vitro cultured sugarcane by culturing on liquid medium. Journal of Agriculture and Food Industry, 9: 418-419. (in Vietnamese with English summary).

Ha Thi Thuy, Le Huy Ham, Do Nang Vinh, 2000b. Studying rapidly multiplying some new sugarcane varieties by culturing callus of young leaf. Journal of Agriculture and Food Industry, 10: 456-458. (in Vietnamese with English summary).

Ha Thi Thuy, Tran Thi Hanh, Do Nang Vinh, 2010. Study on protoplast fusion between Citrus nobilis and sweet orange $C$. sinensis. Journal of Agriculture and Rural Development, 12: 3-9. (in Vietnamese with English summary).

Hoang Ngoc Nhung, Nguyen Thi Quynh, 2015. Study on the root growth of Japanese Angelica acutiloba Kitagawa in liquid medium. Journal of Biotechnology, 13(4A): 1263-1267. (in Vietnamese).

Hoang Thi Giang, Nguyen Quang Thach, Mach Hong Tham, Do Thi Thu Ha, 2010. Study on in vitro propagation and cultivation of $P$. hangianum Perner Gruss collected in Vietnam. Journal of Science and Development, 2: 194-201. (in Vietnamese with English summary).

Hoang Thi Giang, Do Thi Thu Ha, Vu Thi Hang, Nguyen Thi Thuy, Nguyen Quang Thach, Ramona Thieme, Thilo Hammann, 2013. Study on creating and assessing interspecific somatic hybrids between cultivated potato varieties Solanum tuberosum L. $(2 \mathrm{n}=4 \mathrm{x}=48)$ and wild potato lines Solanum bulbocastanum, Solanum tarnli, Solanum 
pinatisectum $(2 \mathrm{n}=2 \mathrm{x}=24)$ bearing resistance to late blight by protoplast fusion. Journal of Agriculture and Rural Development, 22: 3-10. (in Vietnamese with English summary).

Hoang Thi Giang, Nguyen Thi Thuy, Vu Thi Hang, Do Thi Thu Ha, Ramona Thieme, Thilo Hammann, Nguyen Quang Thach, 2014. Resistance to late blight and agronomic properties of hybrids between somatic hybrids and cultivated potatoes. Journal of Science and Development, 12(8): 1302-1313. (in Vietnamese with English summary).

Hoang Thi Lan Xuan, Nguyen Ho Thuy Dung, Nguyen Binh An Thu, Nguyen Phuong Thao, 2014. A study on the expression patterns of GmHKO6 and GmRR34 upon water deficit in MTD777-2 and DT20. Journal of Biology, 36(1se): 232-236. (in Vietnamese with English summary).

Hoang Thi Nga, Nguyen Quang Thach, Do Duc Thinh, Hoang Minh Tu, 2008. Developing a protocol for of rapid propagation of "Hong hoang" orchid (Cymbidium iridioides) by tissue culture technique. Journal of Agricultural Science and Technology, 4: 387-394. (in Vietnamese with English summary).

Hoang Thi Nhu Phuong, Tran Tuan Dat, Tran Van Minh, 2014. In vitro propagation of Anthurium andreanum. Journal of Agriculture and Rural Development, 4: 74-80. (in Vietnamese with English summary).

Hoang Xuan Chien, Ngo Thanh Tai, Nguyen Ba Truc, Tran Xuan Tinh, Lam Bich Thao, Tran Cong Luan, Duong Tan Nhat, 2011. Effect of some factors to in vitro microrhizome formation (Panax vietnamensis $\mathrm{Ha}$ et Grushv.) and determination of plantlet saponin content in Ngoc Linh mountain. Journal of Biotechnology, 9(3): 317-331. (in Vietnamese with English summary).

Hoang N.N., Kitaya Y., Morishita T., Endo R., Shibuya T., 2017. A comparative study on growth and morphology of wasabi plantlets under the influence of the micro-environment in shoot and root zones during photoautotrophic and photomixotrophic micropropagation. Plant Cell Tiss. Org., 130(2): 255-263.

Huynh Thi Thu Hue, Tran Thi Ngoc Diep, Le Thi Thu Hien, Nong Van Hai, 2008. Vector construction and expression assay of cryIA(c) gene in Nicotiana benthamiana leaves. Journal of Biotechnology, 6(4): 453-458. (in Vietnamese with English summary).

Huynh Van Hai, Nguyen Van Uyen, 1981. Clonal propagation of orchid species of genus Cymbidium, Vanda, Spatthiglottis by tissue culture method. Journal of Biology, 3(2): 14-18. (in Vietnamese with English summary).

Kieu Phuong Nam, Cao Quoc Liem, Tran Trung Hieu, Bui Van Le, 2009. A protocol for In vitro propagation of Caribbean pine (Pinus caribaea). Journal of Forestry Science, 1: 854-859. (in Vietnamese with English summary).

Kozai T., Afreen F., Zobayed S.M.A., 2005. Photoautotrophic (sugar free medium) micropropagation as a new propagation and transplant production system. Springer, Dordrecht, The Netherlands, $316 \mathrm{pp}$.

Le Hung Linh, Dinh Xuan Tu, 2017. Research on somatic embryogenesis from in vitro cultured callus of Lai Chau ginseng (Panax vietnamensis var fuscidiscus). Vietnam Journal of Agricultural Science, 2: 76-80. (in Vietnamese with English summary).

Le Huy Ham, Tran Duy Duong, Pham Thi Ly Thu, Le Thi Kim Xuyen, Vu Van Tien, Nguyen Thi Khanh Van, Le Thanh Hoa, 2009. Development of transgenic duckweed expressing VP2 antigen and the preliminary immunological in test chickens. Journal of Biotechnology, 7(3): 341-347. (in Vietnamese with English summary).

Le Quynh Lien, Lam Dai Nhan, Dinh Thi Phong, Le Thi Muoi, Le Tran Binh, 2003. 
An efficient protocol for plant regeneration in papaya (Carica papaya L.) via multi-shoot induction. Journal of Biotechnology, 1(3): 355-362. (in Vietnamese with English summary).

Le Quynh Lien, Phan Trong Hoang, Do Xuan Dong, Chu Hoang Ha, Le Tran Binh, 2008. Expression of rabies virus glycoprotein in transgenic tobacco plants. Journal of Biotechnology, 6(4): 445-452.

Le Thi Bich Thuy, Phan Thi Bay, Le Thi Muoi, Nguyen Duc Thanh, 1997. Production of rice cell lines resisted to culture filtrate of Pyricularia oryzae and regeneration of plants. Journal of Biology, 19(1): 37-42. (in Vietnamese with English summary).

Le Thi Bich Thuy, Dang Thi Minh Lua, Ta Ngoc Ly, Nguyen Thi Kim Lien, Nguyen Duc Thanh, 2007. The effect of gamma rays on the plant generation from irradiated calli and molecular analyses of generated lines. Journal of Biotechnology, 5(2): 225-231. (in Vietnamese with English summary).

Le Thi Diem, Vo Thi Bach Mai, 2017. Effect of plant growth regulators on rapid propagation of in vitro shoot buds of Dachrobium officinale Kimura et Migo. Science and Technology Development Journal (VNU-HCM), 20(2): 29-38. (in Vietnamese with English summary).

Le Thi Kim Dao, 2001. Study on propagation of some forest tree varieties by tissue culture method (Eucalyptus, Paulownia, Michelia mediocris Dandy, Aquilaria crassna). Journal of Biology, 23(3): 46-50. (in Vietnamese with English summary).

Le Thi Muoi, Nguyen Duc Thanh, 1978. Regeneration of whole plants from protoplasts of Nicotiana tabacum L., Ann. Report of Institute of Biology, pp. 88-96. (in Vietnamese with English summary).

Le Thi Muoi, Nguyen Duc Thanh, Do Nang Vinh, 1978. Production of rice plant from in vitro cultured anthers. Journal of Biology and Geography, 16(3): 86-89. (in Vietnamese).

Le Thi Nhu Thao, Hoang Huu Tuan, Mai Thi Phuong Hoa, Do Tien Vinh, Tran Van Minh, 2014. Propagation of Dinh lang (Polyscias fruticosa L. Harms) by shoot tip culture technique. Journal of Medicinal Materials, 19(1): 46-51. (in Vietnamese with English summary).

Le Thi Tam Hong, Tran Van Minh, 2019. Saponin accumulation in suspension culture of Ehretia asperula Zollinger et Moritzi. Journal of Agriculture and Rural Development, 5: 42-47. (in Vietnamese with English summary).

Le Thi Thuy, Le Thu Ngoc, Ho Thi Thuong, Pham Bich Ngoc, Lam Dai Nhan, Chu Hoang Ha, 2017. Study on the transient expression of Hemagglutinin antigen of influenza A/H7N9 virus in Nicotiana benthamiana using agro-infiltration. Journal of Biotechnology, 15(1): 133-140. (in Vietnamese with English summary).

Le Thi Thuy Tien, Bui Trang Viet, Nguyen Duc Luong, 2006. Calli and cell suspension cultures from young leaves and stems of Taxus wallichiana zucc. and the ability of taxol production. Journal of Biotechnology, 4(2): 221-226. (in Vietnamese with English summary).

Le Thi Xuan, Nguyen Duc Thanh, Nghiem Nhu Van, 1978. The results on the use of tissue culture for production of homozygotic lines in Nicotiana tabacum L., Ann. Report of Institute of Biology, pp. 66-74. (in Vietnamese with English summary).

Le Thi Xuan, Le Thi Muoi, Nguyen Duc Thanh, Tran Ngoc Cat, 1979. The obtain of dihaploid lines in Nicotiana tabacum by tissue culture technique. Journal of Agriculture Science and Technique, 199: 17-21. (in Vietnamese).

Le Thi Xuan, 1985. Improvement of culture condition and regeneration of plants from protoplast of Arabidopsis thaliana L. 
Journal of Biology, 7(2): 1-4. (in Vietnamese with English summary).

Le Tran Binh, 1983. The result on production of homologous tobacco lines by the haploid method. Journal of Biology, 5(2): 4-8. (in Vietnamese with English summary).

Le Tran Binh, 1991. Transferring of cytoplasmic male sterility (CMS) into Cao Bang 2 tobacco plant by using protoplast fusion. Journal of Biology, 12(2): 1-6. (in Vietnamese with English summary).

Le Trong Lu, Nguyen Thuy Phuong Duyen, Hoang Ngoc Nhung, Pham Minh Duy, Nguyen Thi Quynh, 2015. Effects of NH4NO3 and KNO3 content on the growth of Lavandula angustifolia under photoautotrophic culture. Journal of Biotechnology, 13(4A): 1313-1319. (in Vietnamese with English summary).

Le Van Thanh, Nguyen Thi Hien, 2010. Micropropagation of Aquilaria crassna Pierre by tissue culture. Vietnam Journal of Forestry Science, 4: 1-6. (in Vietnamese with English summary).

Le Xuan Tu, Nguyen Thi Xuan Giang, 1981. Effect of gamma rays on the development of soybean callus. Journal of Biology, 3(4): 7-11. (in Vietnamese with English summary).

Le Xuan Tu, Nguyen Thi Xuan Giang, 1982. Effects of gamma rays on callus formation form anthers of rice and regeneration of rice plants from callus. Journal of Biology, 4(3): 16-18. (in Vietnamese with English summary).

Mai Thi Phuong Hoa, Bui Thi Tuong Thu, Tran Van Minh, 2011. Industrial propagation of Dendrobium sp., Phalaenopsis sp., Cymbidium sp. and Rhynchostylis sp. by immersion bioreactor technique. Journal of Biology, 33(2): 8288. (in Vietnamese with English summary).

Mai Thi Phuong Hoa, Bui Thi Tuong Thu, Tran Van Minh, 2012. Hair root culture of Artemisia annua L. in semi-solid and liquid media. Journal of Medicinal
Materials, $\quad$ 17(4): 254-258. (in Vietnamese with English summary).

Mai Truong, Nguyen Huu Ho, Le Tan Duc, Nguyen Van Uyen, 2001. A Study on regeneration and gene transfer in green peas (Vigna radiate L.). Part I: Regeneration of green pea plants from in vitro cultured cotyledon. Journal of Biology, 23(1): 33-35. (in Vietnamese with English summary).

Mai Truong, Tran Thi Ngoc Ha, Phan Tuong Loc, Le Tan Duc, Tran Trong Tuan, Do Dang Giap, Bui Dinh Thach, Pham Duc Tri, Nguyen Duc Minh Hung, Nguyen Thi Thanh, Nguyen Van Ket, Tran Cong Luan, Nguyen Huu Ho, 2013. The study on in vitro culture of embryogenic callus and somatic embryo tissue of Panax vietmamensis Ha et Grushv. Journal of Biology, 35(3se): 145-157. (in Vietnamese with English summary).

Nghiem Ngoc Minh, Nguyen Duc Thanh, Phan Thi Bay, Dao Xuan Hai, Le Thi Muoi, 1992. Micropropagation of Carnation. Journal of Biology, 14(3): 33-36. (in Vietnamese with English summary).

Nghiem Ngoc Minh, Nguyen Duc Thanh, Le Thi Muoi, Medgyesy Peter, 1997. Preliminary results on production of hybrids plants by protoplast fusion between Nicotiana tabacum and Solanum nigrum. Ann. Report of Institute of Biotechnology, pp. 246-252. (in Vietnamese with English summary).

Nghiem Ngoc Minh, Le Thi Muoi, Nguyen Duc Thanh, Peter Medgyesy. 1999. Gene transfer by co-culture of Agrobacterium tumefaciens with Nicotiana plumbaginifolia protoplast. Journal of Biology, 21(1b): 113-116. (in Vietnamese with English summary).

Nghiem Nhu Van, 1989. The formation of callus from pollen grains inside rice anthers cultured in vitro. Journal of Biology, 11(2): 27-30. (in Vietnamese with English summary). 
Nghiem Nhu Van, Le Xuan Dac, Le Tran Binh, Le Thi Muoi, 2002. Production of homologous lines by anther culture of heterosis lines of rice. I. Anther culture of heterosis lines of rice. Journal of Biology, 24(1): 44-49. (in Vietnamese with English summary).

Nghiem Nhu Van, Le Tran Binh, Le Thi Muoi, 2004. Two perspective double haploid rice lines $\mathrm{VH} 1$ and $\mathrm{VH} 2$ obtained by anther culture. Journal of Biology, 26(4): 35-39. (in Vietnamese with English summary).

Nghiem Nhu Van, Cao Thi Loi, Le Tran Binh, 2006. The national trial and trial production of two quality rice lines $\mathrm{VH} 1$ and $\mathrm{VH} 2$ obtained by haploid selectionanther culture method. Journal of Biology, 28(2): 57-62. (in Vietnamese with English summary).

Ngo Thi Ngoc Huong, Dinh van Khiem, Nguyen Thi Quynh, 2015. Effect of mineral contents on the growth of Vietnamese ginseng (Panax vietnamensis Ha et Grushv.) cultured in vitro under photoautotrophic condition. Journal of Biology, 37(1): 96-102. (in Vietnamese with English summary).

Nguyen Ba Nam, Nguyen Phuc Huy, Vu Quoc Luan, Hoang Thanh Tung, Duong Tan Nhut, 2016. Application of wireless power transmission led lighting system in propagation of chrysanthemum and strawberry. Planta Daninha, 34(4): 617-630.

Nguyen Binh An Thu, Hoang Thi Lan Xuan, Nguyen Phuong Thao, 2014. Studies on expression of transcriptional factor genes GmNAC092, GmNAC083 and GmNAC057 in response to drought stress of two soybean varieties Williams 82 and Mtd777-2 for enhancing drought tolerance by genetic engineering. Journal of Biology, 36(1se): 244-249. (in Vietnamese with English summary).

Nguyen Duc Thanh, Le Thi Muoi, 1981. The Results on protoplast culture in Nicotiana tabacum and Solanum tuberosum. Ann.
Report of Institute of Biology, pp. 71-76. (in Vietnamese with English summary).

Nguyen Duc Thanh, 1983. The culture of protoplasts isolated from tetraploid clones of Solanum tuberosum: callus proliferation and plant regeneration. Journal of Biology, 5(3): 13-15. (in Vietnamese with English summary).

Nguyen Duc Thanh, Medgyesy P., 1988. Transfer of streptomycin resistance and cytoplasmic male sterility in Nicotiana tabacum through protoplast fusion. Journal of Biology, 10(2): 1-6. (in Vietnamese with English summary).

Nguyen Duc Thanh, Medgyesy P., 1989. Intra- and intersubfamilial chloroplast transfer by protoplast fusion within Solanaceous species. Journal of Biology, 11(1): 9-15. (in Vietnamese with English summary).

Nguyen Duc Thanh, Tran Thanh Thu, Nghiem Ngoc Minh, Tran Thi Thu Hong, Le Thi Muoi, 1991. The study of variation of nicotine in callus culture and in vitro cultured plants of Nicotiana tabacum having different plastid types. Journal of Biology, 13(4): 37-40. (in Vietnamese with English summary).

Nguyen Duc Thanh, Medgyesy P., 1993. High frequency plastid transformation and plant regeneration by PEG-treated protoplasts of Nicotiana tabacum. Proc. Natl. Cent. Natur. Sci. Tech. Vietnam, 5(2): 97-102.

Nguyen Duc Thanh, Phan Thi Bay, Le Thi Muoi, 1994. Chloroplast transformation in Nicotiana species. Ann. Report of Institute of Biotechnology, pp. 38-41. (in Vietnamese with English summary).

Nguyen Duc Thanh, Nghiem Ngoc Minh, Le Thi Muoi, 1996. Primary results on production of new chloroplast combination in Nicotiana by protoplast fusion. Journal of Biology, 18(2): 37-38. (in Vietnamese with English summary).

Nguyen Duc Thanh, Nghiem Ngoc Minh, Le Thi Muoi, 1997. Transfer of chloroplast genes from Solanum nigrum 
into Nicotiana plumbaginifolia plants. Ann. Report of Institute of Biotechnology, pp. 239-245. (in Vietnamese with English summary).

Nguyen Duc Thanh, Le Thi Muoi, Dao Xuan Hai, 2003. The protocol of rapid multiplication of Cayenne pineapples by in vitro tissue culture method. Patent No. 333. Intellectual Property Office of Vietnam. (Ministry of Science and Technology).

Nguyen Duc Thanh, Dang Thi Minh Lua, Quach Thi Lien, 2012. Regeneration of complete Lyptostrobus pensilis (Staunton ex D. Don) K. Koch plants from in vitro derived shoots. Journal of Biology, 34(2): 228-234. (in Vietnamese with English summary).

Nguyen Duc Thanh, Tran Thi Luong, Nguyen Thuy Ninh, Nguyen Thi Thu, Ho Thi Huong, Vuong Huy Minh, 2015. Transgenic maize plant with enhanced starch content and yield. Journal of Biology, 37(4): 496-502. (in Vietnamese with English summary).

Nguyen Duy Phuong, Phan Tuan Nghia, Pham Xuan Hoi, 2015. Study on genetic transformation of Indica rice (Oryza sativa Indica) with drought responsive OsNLI-IF gene. Journal of Biotechnology, 13(3): 875-884. (in Vietnamese with English summary).

Nguyen Hoang Loc, Le Thi Muoi, Le Tran Binh, 1990. Select Nicotiana tabacum L. tobacco line resistant to $\mathrm{NaCl}$ by callus culture. Journal of Biology, 12(3): 16-20. (in Vietnamese with English summary).

Nguyen Hoang Loc, Ngo Anh, Tran Thien an, 1997. In vitro propagation of Aquilaria crassma Pierre. Journal of Biology, 19(4): 49-50. (in Vietnamese with English summary).

Nguyen Hoang Loc, Ngo Anh, Doan Nhan Ai, Vuong Quang Man, Dang Quang Bang, 2001. Propagation of Camellia japonics L.) by cutting method. Journal of Biology, 23(2): 39-44. (in Vietnamese with English summary).
Nguyen Hoang Loc, Truong Thi Bich Phuong, Dang Thi Thu Thuy, Nguyen Huu Dong, 2003. Selection of Saccharum officinarum L. lines that tolerate to drought through callus culture. Journal of Biology, 25(1A): 112-118. (in Vietnamese with English summary).

Nguyen Hoang Loc, Tran Thi Trieu Ha, Yutaka Hirata, 2006. Effect of several factors on cell biomass production of Zedoary (Curcuma zedoaria Roscoe) in bioreactor. Journal of Biotechnology, 4(2): 213-220.

Nguyen Hoang Loc, Nguyen Thi Tam An, 2010. Asiaticoside production from cell culture of centella (Centella asiatica L. Urban). Biotechnol. Bioproc. E., 15: 1065-1070.

Nguyen Hoang Loc, Le Thi Ha Thanh, 2011. Solasodine production from cell culture of Solanum hainanense Hance. Biotechnol. Bioproc. E., 16: 581-586.

Nguyen Hoang Loc, Nguyen Thi Duy Nhat, 2013. Production of asiaticoside from centella (Centella asiatica L. Urban) cells in bioreactor. Asian Pac. J. Trop. Biomedicine, 3(10): 806-810.

Nguyen Hoang Loc, Nguyen Huu Thuan Anh, Le Thi Minh Khuyen, Ton $\mathrm{Nu}$ Thuy An, 2014. Effects of yeast extract and methyl jasmonate on the enhancement of solasodine biosynthesis in cell cultures of Solanum hainanense Hance. J. BioSci. Biotech., 3(1): 1-6.

Nguyen Hoang Loc, Nguyen Thanh Giang, Nguyen Duc Huy, Truong Thi Phuong Lan, 2017. Accumulation of madecassoside - a major component of centelloside in centella (Centella asiatica (L.) Urban) cells elicited by salicylic acid. Period. Biol., 119(1): 81-85.

Nguyen Hong $\mathrm{Vu}$, Phan Hoang Anh, Duong Tan Nhut, 2006. The role of sucrose and different cytokinins in the in vitro floral morphogenesis of rose (hybrid tea) cv. "First Prize". Plant Cell Tiss. Org., 87(3): 315-320. 
Nguyen Huy Hoang, Pham Bich Ngoc, Chu Hoang Ha, Le Van Son, 2017. Transient expression of interleukin-7 in by-2 tobacco cell line. Journal of Biotechnology, 15(3): 541-546. (in Vietnamese with English summary).

Nguyen Huu Nhan, Nguyen Hoang Loc, 2017. Production of eurycomanone from cell suspension culture of Eurycoma longifolia Jack. Pharm. Biol., 55(1): 2234-2239.

Nguyen Huu Nhan, Nguyen Hoang Loc, 2018. Enhancement of eurycomanone biosynthesis in cell culture of longjack (Eurycoma longifolia) by elicitor treatment. J. Plant Biotech., 45(4): 340-346.

Nguyen Huu Thuan Anh, Ton Nu Thuy An, Nguyen Thuan Nho, Vo Thi Vien Dung, Nguyen Hoang Loc, 2016. Effect of salicylic acid on the biosynthesis of solasodine in cell suspension culture of Solanum hainanense Hance. Plant Cell Biotechnol. Mol. Biol., 17(1-2): 14-20.

Nguyen Kim Lan, Le Thi Xuan, Mai Van Tri, Nguyen Duc Thanh, 1996. Preliminary results on tissue culture of Taxus wallchiana. Ann. Report of Institute of Biotechnology, pp. 54-58. (in Vietnamese with English summary).

Nguyen Kim Lan, Phan Thi Bay, Dao Xuan Hai, Le Thi Muoi, Nguyen Duc Thanh, 1998. Rapid propagation of high yield sugarcane via plant in vitro technology. Ann. Report of Institute of Biotechnology, pp. 392-399. (in Vietnamese with English summary).

Nguyen Minh Hung, Chu Hoang Ha, Le Tran Binh, 2006. An efficient protocol for papaya (Carica papaya L.) regeneration via somatic embryogenesis induction. Journal of Biotechnology, 4(2): 233-239. (in Vietnamese with English summary).

Nguyen Minh Khoi, Pham Thanh Huyen, Nguyen Quynh Nga, Nguyen Xuan Truong, Pham Ngoc Khanh, Truong Quang Luc, Ta Quoc Vuong, Le Hung Tien, Vu Hoai Sam, 2017. Research results on conservation of medicinal plant genetic resources in Vietnam in the period of 2011-2016. Proceeding of the $7^{\text {th }}$ National Scientific Conference on Ecology and Biological Resources, Hanoi 2017: pp. 1258-1264. (in Vietnamese with English summary).

Nguyen Ngoc Dung, Nguyen Van Uyen, 1997. Clonal propagation of Polyscias fruticosa L. by somatic embryogenesis. Journal of Biology, 19(3): 28-30. (in Vietnamese with English summary).

Nguyen Nhu Hien, Huynh Huu Duc, Nguyen Dinh Sy, Nguyen Thi Quynh, 2009. Effects of photoperiods on in vitro growth of Dendrobium Burana White in photoautotrophic micropropagation. Journal of Science and Technology of Agriculture and Forestry, 3: 11-14. (in Vietnamese with English summary).

Nguyen Nhu Hien, Nguyen Thi Quynh, 2010. The effect of temperature and humidity on the growth and secondary compound accumulation in Phyllanthus amarus Schum. \& Thonn.) In in vitro autophototropic culture. Proceedings of the National Biotechnology Conference in the South, 24-25/10/2009, Ho Chi Minh City, pp. 138-142. (in Vietnamese with English summary).

Nguyen Quang Thach, Hoang Thi Nga, 2000. Study on applying thin cell layer culture in fast multiplying Vanda, Cattleya and Phaleanopsis. Journal of Agriculture and Food Industry, 12: 546-548. (in Vietnamese).

Nguyen Quang Thach, Hoang Thi Nga, Nguyen Thi Ly Anh, Le Thi Muoi, 2004. In vitro propagation of Cymbidium orchid miss Kim. Journal of Agriculture-Rural-Environment, 11: 1503-1505. (in Vietnamese).

Nguyen Quang Thach, Nguyen Xuan Truong, Nguyen Thi Ly Anh, Pham Van Tuan, Lai Duc Luu, 2005. Production of potato minituber tubers from in vitro plants. Journal of Agricultural Science and 
Technology, 3: 46-49. (in Vietnamese with English summary).

Nguyen Quang Thach, Phi Thi Cam Mien, 2012. Study on in vitro propagation of Anoectochilus setaveus Blume for conservation of precious medicinal herbs. Journal of Science and Development, 10(4): 597-603. (in Vietnamese with English summary).

Nguyen Quynh Trang, Vu Thi Hue, Khuat Thi Hai Ninh, Nguyen Thi Tho, 2013. In vitro propagation Dendrobium anosmum. Journal of Forestry Science and Technology, 3(1): 16-21. (in Vietnamese with English summary).

Nguyen Thanh Giang, Nguyen Duc Huy, Le Thi Ha Thanh, Nguyen Hoang Loc, 2016. Efficiency of the combination of salicylic acid, yeast extract and methyl jasmonate on asiaticoside production in centella (Centella asiatica (L.) Urban) cells. Plant Cell Biotechnol. Mol. Biol., 17(1-2): 64-71.

Nguyen Thanh Tung, Le Van Diep, Nguyen Minh Trung, Truong Thi Bich Phuong, 2010. Application of thin cell layer culture method in micropropagation of Dendrobium aduncum. Journal of Biotechnology, 8(3): 361-367. (in Vietnamese with English summary).

Nguyen Thanh Sum, Pham Ngoc Tuan, Nguyen Van Ket, 2007. Application of micropropagation in conservation of Lyptostrobus pensilis (Staunton ex) K. Koch). Journal of Science and Technology of Agriculture and Forestry (University of Agriculture and Forestry, HCM City), 1\&2: 75-81. (in Vietnamese with English summary).

Nguyen The Huong, Bui The Doi, Nguyen Thi Huong, Ha Bich Hong, 2017. Selection of Eucalyptus lines carrying somatic variation that tolerate to drought. Journal of Forestry Science and Technology, 1: 3-10. (in Vietnamese with English summary).
Nguyen Thi Dieu Huong, Duong Tan Nhut, 2004. Rapid propagation of Chrysanthenum indicum L.) by meristem cultures. Journal of Biology, 26(4): 45-48. (in Vietnamese with English summary).

Nguyen Thi Hai Yen, Pham Thi Van, Chu Hoang Ha, Chu Hoang Mau, Le Tran Binh, 2011. Development of tomato PT18 plants resistant to tomato yellow leaf curl virus by RNAi technology. Journal of Biotechnology, 9(3): 333-340. (in Vietnamese with English summary).

Nguyen Thi Kim Loan, Do Dang Giap, Tran Trong Tuan, Nguyen Thi Thanh Hien, Nguyen Phuc Huy, Thai Xuan Du, Duong Tan Nhut, 2016. Primary and secondary somatic embryogenesis in Jatropha curcas L. from leaf transverse thin cell layers. Journal of Biotechnology, 14(4): 661-671.

Nguyen Thi Kim Thanh, 2005. Propagation of roses by in vitro culture technique. Journal of Agriculture and Rural Development, 1: 39-41. (in Vietnamese with English summary).

Nguyen Thi Lien Chi, Nguyen Van Uyen, 1989. Regeneration of plants from Solanum laciniatum Ait protoplasts. Journal of Biology, 11(3): 1-3. (in Vietnamese with English summary).

Nguyen Thi Ly Anh, Nguyen Thi Huong, Nguyen Quang Thach, 2005. Study on production of lily bulbs in vitro and growth of lily plants from in vitro bulbs. Journal of Agriculture and Rural Development, 1: 33-35. (in Vietnamese with English summary).

Nguyen Thi Minh Hang, Ho Thi Thuong, Nguyen Thu Giang, Pham Thi Van, Pham Bich Ngoc, Nguyen Trung Nam, Chu Hoang Ha, 2017. Expression and purification of protein $\mathrm{M}$ of pathogenic PRRS by transient expression technology in tobacco leaves of Nicotiana benthamiana. Journal of Biotechnology, 15(3): 547-554. (in Vietnamese with English summary). 
Nguyen Thi Nhat Linh, Hoang Thanh Tung, Nguyen Hoang Loc, Duong Tan Nhut, 2017. The effect of biotic and abiotic elicitors on biomass and saponin production of secondary root cultivated in shake flasks Panax vietnamensis adventitious root. Journal of Biotechnology, 15(2): 285-291. (in Vietnamese with English summary).

Nguyen Thi Nhat Linh, Le Kim Cuong, Ho Thanh Tam, Hoang Thanh Tung, Vu Quoc Luan, Vu Thi Hien, Nguyen Hoang Loc, Duong Tan Nhut, 2019. Improvement of bioactive saponin accumulation in adventitious root cultures of Panax vietnamensis via culture periods and elicitation. Plant Cell Tiss. Org., 137(1): 101-113.

Nguyen Thi Phuong Thao, Nguyen Quang Thach, 2005. The application of the thin cell layer culture technique in production of initial material for rapid propagation of Lilium formolongo. Journal of Biotechnology, 3(4): 495-502. (in Vietnamese with English summary).

Nguyen Thi Phuong Thao, Nguyen Quang Thach, Hoang Thi Mai, 2006. Rapid propagation of Lilium formolongo by in vitro culture technique. Journal of Biotechnology, 4(1): 117-123. (in Vietnamese with English summary).

Nguyen Thi Phuong Thao, Do Thi Thu Ha, Vu Thi Hang, Hoang Thi Giang, Nguyen Quang Thach, 2012. Study on isolation, cultivation and regeneration of protoplasts of diploid potato for varietal production by protoplast fusion. Journal of Agriculture and Rural Development, 2: 46-54. (in Vietnamese with English summary).

Nguyen Thi Phuong Thao, Dang Quang Bich, Nguyen Thi Thuy, Nguyen Thi Thuy Linh, Pham Thi Thu Hang, Dang Thi Thanh Tam, Ninh Thi Thao, Nguyen Thi Lam Hai, Nguyen Thanh Hai, 2015. Rapid propagation and induction of flowering in rose (Rosa sericea LINDL). Journal of Science and Development, 13(4): 606-613. (in Vietnamese with English summary).
Nguyen Thi Quynh, Nguyen Van Uyen, 1985. Culture of apical buds of taro plant (Colocasia antiquorum). Journal of Biology, $\quad 7(4)$ : 37-38. (in Vietnamese with English summary).

Nguyen Thi Quynh, Nguyen Van Uyen, 1987. Aroids propagation by tissue culture, I. Shoot tip culture and propagation of Xanthosoma violaceum. Hort. Sci., 22(4): 671-672.

Nguyen Thi Quynh, Nguyen Van Uyen, 1993a. Rapid multiplication of coffee by in vitro and nursery bed vegetative propagation. In: Nguyen Thi Quynh, Nguyen Van Uyen (eds.) Adapted propagation techniques for commercial crops of the tropics. Proc. of the Southeast Asian Regional Workshop on Propagation Techniques for Commercial Crops of the Tropics, organized by International Foundation for Science (IFS) at Ho Chi Minh City, Vietnam, Feb. 7-12, 1993. Agricultural Publishing House, Ho Chi Minh City, Vietnam, pp. 216-223.

Nguyen Thi Quynh, Nguyen Van Uyen, 1993b. Micropropagation of coffee trees. In: Nguyen Van Uyen "Plant tissue culture for plant breeding". Agricultural Publishing House, Ho Chi Minh, pp. 53-64. (in Vietnamese with English summary).

Nguyen Q. T., Kozai T, Niu G, Nguyen U. V., 1999. Photosynthetic characteristics of coffee (Coffea arabusta) plantlets in vitro in response to different $\mathrm{CO}_{2}$ concentrations and light intensities. Plant Cell Tiss. Org., 55: 133-139.

Nguyen Q. T., Hoang T. V., Nguyen H. N., Nguyen S. D., Huynh D. H., 2010a. Photoautotrophic growth of Dendrobium 'Burana White' under different light and ventilation conditions. Propag. Ornam. Plants, 10(4): 227-236.

Nguyen Thi Quynh, Hoang Minh Tuan, Nguyen Nhu Hien, 2010b. The effect of sugar concentration, ventilation and light intensity on the growth of Plectranthus amboinicus in photoautotrophic culture in nylon bags with gas exchange membranes. 
Proceedings of the National Biotechnology Conference in the South, October 24-25, 2009, Science and Technology Publishing House, Ho Chi Minh City, pp. 297-301. (in Vietnamese with English summary).

Nguyen Q. T., Kozai T., Heo J., Thai X. D., 2001. Photoautotrophic growth response of in vitro coffee plantlets to ventilation methods and photosynthetic photon fluxes under carbon dioxide enriched condition. Plant Cell Tiss. Org., 66: 217-225.

Nguyen Thi Quynh, Nguyen Thi Kim Linh, Thai Xuan Du, Doan Thi Ai Thuyen, 2002. Effects of nutrient concentration and ventilation condition of the culture vessel on the growth of Paulownia (Paulownia fortunei) cultured in vitro. Adv. Nat. Sci., 3(3): 281-287.

Nguyen Thi Quynh, Le Tan Hung, Thai Xuan Du, Kozai T., 2002. Growth enhancement of in vitro yam (Dioscorea alata) plantlets under photoautotrophic condition using a forced ventilation system. In: Nakatani M, Komaki K (eds.) Potential of root crops for food and industrial resources. Proceedings of the $12^{\text {th }}$ Symposium of the International Society for Tropical Root Crops (ISTRC), September 10-16, 2000, Tsukuba, Japan. Cultio Corporation, Ibaraki, Japan, pp. 366-368.

Nguyen Q. T., Kozai T., 2005. Photoautotrophic micropropagation of woody species. In: Kozai T, Zobayed SMA, Afreen-Zobayed F (eds.) Photoautotrophic (sugar-free medium) micropropagation as a new micropropagation and transplant production system. Springer, Dordrecht, The Netherlands, pp. 119-142.

Nguyen Q. T., Kozai T., 2007. Effects of temperature and nodal cutting position on the growth of in vitro cultured coffee plants under photoautotrophic conditions. Jap. J. Trop. Agr., 51(1): 5-11.

Nguyen Q. T., Xiao Y., Kozai T., 2016. Photoautotrophic micropropagation. In: Kozai T., Niu G., Takagaki M. (eds.) Plant Factory - An indoor vertical farming system for efficient quality food production ( $1^{\text {st }}$ edition). Academic Press, Elsevier. California, USA, pp. 271-283.

Nguyen Q. T., Xiao Y., Kozai T., 2020. Photoautotrophic micropropagation. In: Kozai T., Niu G., Takagaki M. (eds.) Plant Factory-An indoor vertical farming system for efficient quality food production ( $2^{\text {nd }}$ edition). Academic Press, Elsevier. California, USA, pp. 333-346.

Nguyen Thi Son, Nguyen Thi Ly Anh, Vu Ngoc Lan, Tran The Mai, 2012a. In vitro propagation of Dendrobium fimbriatum. Journal of Science and Development, 10(2): 263-271. (in Vietnamese with English summary).

Nguyen Thi Son, Tran the Mai, Hoang Thi Nga, Nguyen Thi Ly Anh, Nguyen Quang Thach, 2012b. Application of Plantima bioreactor system in propagation of Dendrobium nobile L.. Journal of Agriculture and Rural Development, 22(2): 28-34. (in Vietnamese with English summary).

Nguyen Thi Son, Nguyen Quang Thach, Nguyen Thi Ly Anh, Hoang Thi Nga, Hoang Thi Anh Nguyet, 2014. Clonal propagation of Phalaenopsis Sogo Yukidian orchids. Journal of Science and Development, 12(8): 1283-1293. (in Vietnamese with English summary).

Nguyen Thi Thu Nga, Le Tran Binh, 2012. Establishment of a system for regeneration and transformation in peanut (Arachis hypogaea L.) using somatic embryo. Journal of Biology, 34(3): 370-376. (in Vietnamese with English summary).

Nguyen Thi Thu Nga, Pham Thi Thanh Nhan, Le Van Son, Le Tran Binh, 2015. Expression NAC2 protein related to drought tolerance from peanut varieties L12 in tobacco. Journal of Biotechnology, 13(4): 1101-1106. (in Vietnamese with English summary).

Nguyen Thi Thu, Nguyen Thuy Ninh, Tran Thi Luong, Nguyen Duc Thanh, 2014. Genetic transformation of inbred maize lines using meristem and Agrobacterium 
tumefaciens. Journal of Biotechnology, 12(4): 691-698. (in Vietnamese with English summary).

Nguyen Thi Thuy Diem, 2015. Propagation of Anthurium andreanum L. by thin cell layer culture method. Journal of Science (Can Tho University), 7(3): 105-114. (in Vietnamese with English summary).

Nguyen Thu Hien, Chu Hoang Mau, Hoang Ha, Le Van Son, Chu Hoang Ha, 2013. Expression of H5N1 virus antigen HA in soybean seeds. Journal of Biotechnology, 11(1): 115-120. (in Vietnamese with English summary).

Nguyen Thuy Phuong Duyen, Hoang Ngoc Nhung, Nguyen Thi Quynh, 2015. Studying the root growth of Coleus forskohlii cultured photoautotrophically on different supporting materials and identifying forskolin accumulated in roots by HPLC. Journal of Biotechnology, 13(3): 939-944. (in Vietnamese with English summary).

Nguyen Thuy Phuong Duyen, Tran Thi Van, Nguyen Le Thu Minh, Nguyen Thi Quynh, 2017. Effects of microenvironmental factors on the photoautotrophic growth of Hibiscus sagittifolius Kurz cultured in vitro. Journal of Biology, 39(4): 496-506.

Nguyen T. N., Tran T. L., Nguyen D. T., 2016. Agrobacterium-mediated transformation of five inbred maize lines with the Brittle 2 gene. Turk. J. Biol., 40: 755-761.

Nguyen Tri Minh, Nguyen Thi Quynh, Nguyen Van Uyen, 2008. Effects of $\mathrm{CO}_{2}$ concentrations and light intensities on the growth of in vitro and ex vitro strawberry plantlets (Fragaria ananassa Duch.). Journal of Biotechnology, 6(2): 233-239. (in Vietnamese with English summary).

Nguyen Trung Hau, Le Thi Nhu Thao, Tran Van Minh, 2015. Cultivation of leaf-tissue of Polyscias fruticosa (L.) Harms for quantity of saponin accumulation. Journal of Biology, 37(1se): 184-189. (in Vietnamese with English summary).
Nguyen Van Dong, Pham Thi Ly Thu, Trinh Thi Minh Thuy, Ta Kim Nhung, Vuong Huy Minh, Phan Xuan Hao, Le Thi Thu Ve, Le Huy Ham, Do Nang Vinh, 2009. Study on induction of embryogenic callus and plant regeneration capacity from immature embryos of Vietnam maize lines. Journal of Biotechnology, 7(4): 463-470. (in Vietnamese with English summary).

Nguyen Van Dong, Nguyen Huu Kien, Tran Thu Cuc, 2012. Preliminary results in the study on transferring of insect resistance gene crylb in soybean. Vietnam Journal of Agricultural Science and Technology, 9(39): 125-131. (in Vietnamese with English summary).

Nguyen Van Dong, Le Huy Ham, Choi JungDo, Le Tien Dung, 2013. Redesigning the enzyme Acetohydroxy acid synthase for the production of herbicide resistant transgenic plants. Journal of Agriculture and Rural Development, 8: 43-47. (in Vietnamese with English summary).

Nguyen Van Dong, Pham Thi Ly Thu, Le Thi Mai Huong, Pham Thi Huong, Le Thi Lan, Nguyen Chien Huu, Nguyen Huu Kien, Tran Duy Hung, Le Huy Ham, 2015. Transferring drought-resistant gene $N F-Y B 2$ into selected Vietnam maize lines. Journal of Agriculture and Rural Development, 7: 25-30. (in Vietnamese with English summary).

Nguyen Van Ket, Nguyen Van Minh, 2010. Study on In vitro propagation of Dendrobium crepidatum Lindl. \& Paxt. Journal of Science and Technology, 48(5): 89-95. (in Vietnamese with English summary).

Nguyen Van Song, Phan Hung Vinh, Truong Thi Bich Phuong, 2011. Rapid in vitro propagation of Dendrobium chrysotoxum-an endangered wild orchid species. Journal of Science (Hue University), 64: 127-136. (in Vietnamese with English summary).

Nguyen Van Viet, 2017. Study on in vitro propagation of Sapa ancient roses (Rosa sp.) for the conservation and 
development of genetic resources. Journal of Agriculture and Rural Development, 19: 76-81. (in Vietnamese with English summary).

Pham Bich Ngoc, Nguyen Dinh Trong, Nguyen Khac Hung, Nguyen Thi Thuy Huong, Lam Dai Nhan, Nguyen Huu Cuong, Le Tran Binh, Duong Tan Nhut, Chu Hoang Ha, 2013. Agrobacterium rhizogenes-mediated hairy root formation in Ngoc Linh ginseng (Panax vietnamensis Ha et Grushv.). Journal of Biotechnology, 11(4): 689-695. (in Vietnamese with English summary).

Pham Duc Tri, Nguyen Thi Thanh, Nguyen Huu Ho, 2014. Expression of HIV-1-p24 gene in transplastomic tomato (Lycopersicon esculentum Mill.) plant. Journal of Biotechnology, 12(2): 281-288. (in Vietnamese with English summary).

Pham Minh Duy, Nguyen Nhu Hien, Hoang Ngoc Nhung, Nguyen Du Sanh, Nguyen Thi Quynh, 2012. growth promotion and secondary metabolite accumulation of Phyllanthus amarus cultured photoautotrophically under $\mathrm{CO}_{2}$ enriched condition. Journal of Biology, 34(3se): 249-256. (in Vietnamese with English summary).

Pham Minh Duy, Nguyen Thị Quynh, 2014. Growth and lignan accumulation of Phyllanthus amarus (Schum. \& Thonn.) cultured in vitro photoautotrophically as affected by light intensity and photoperiod. Journal of Biology, 36(2): 203-209. (in Vietnamese with English summary).

Pham Thi Kim Hanh, Doan Duy Thanh, Ha Thi Thuy, Do Nang Vinh, 2009. Results of in vitro propagation of Rhynchostylis gigantea in bioreactor. Journal of Agriculture and Rural Development, 3: 46-50. (in Vietnamese with English summary).

Pham Thi Ly Thu, Le Huy Ham, Do Nang Vinh, 2001. Direct gene Transfer into protoplasts of $B$. oleracea L. var. Botrytis through PEG. Journal of Agriculture and Rural Development, 11: 792-793. (in Vietnamese with English summary).
Pham Thi Ly Thu, Le Huy Ham, 2003. Transforming genes into Brassica napus through polyethylene glycol. Journal of Agriculture and Rural Development, 10: 1270-1272. (in Vietnamese with English summary).

Pham Thi Ly Thu, Nguyen Thi Hoa, Pham Thi Huong, Le Thi Lan, Nguyen Van Dong, Le Huy Ham, 2013. Study on transfer of insect resistance genes into immature embryos of F1 hybrid maize lines. Journal of Vietnam Agricultural Science and Technology, 2(41): 55-60. (in Vietnamese).

Pham Thi Ly Thu, Pham Thi Huong, Le Thi Lan, Nguyen Van Dong, Le Huy Ham, 2015. Study on transfer of herbicide resistance gene into some Vietnamese maize lines. Journal of Agriculture and Rural Development, 6: 23-28. (in Vietnamese with English summary).

Pham Thi My Lan, Nguyen Xuan Cuong, 2014. Study on some factors affecting the rate, generation, generation, rapid multiplication of pre-embryos and making somatic embryos of Pinus merkusii under in vitro conditions. Vietnam Journal of Forestry Science, 4: 3491-3498. (in Vietnamese with English summary).

Pham Thi Van, Chu Hoang Ha, Le Tran Binh, 2009. Transgenic Nicotiana tabacum plants carrying RNAi construct resistant to two mosaic viruses. Journal of Biotechnology, $\quad 7(2)$ : 193-201. (in Vietnamese with English summary).

Pham Thu Hang, Dam Quang Hieu, Phan Tuan Nghia, Pham Xuan Hoi, 2016. Construction of vector and transformation of drought-responsive gene OsNAC1 into J02 (Oryza sativa L. japonica) rice. Journal of Biotechnology, 14(2): 271-277. (in Vietnamese with English summary).

Phan Duy Hiep, Nguyen Tri Minh, Phan Xuan Huyen, Cao Dinh Hung, Dinh Van Khiem, Nguyen Thi Thanh Hang, 2014. A study on effects of plant growth regulators on the morphogenesis of Hibiscus sagittifolius 
Kurz under in vitro conditions. Journal of Biology, 36(1se): 266-271. (in Vietnamese with English summary).

Phan Huy Bao, Le Thi Xuan, 1986. Regeneration of Panax pseudoginseng plants via somatic embryogenesis in cultured calli. Journal of Biology, 8(1): 1114. (in Vietnamese with English summary).

Phan Thi Bay, Dao Xuan Hai, Le Bich Thuy, Do Thu Hien, Nguyen Viet Hai, Le Thi Muoi, Nguyen Duc Thanh, 1994a. In vitro micropropagation of pineapple (Anana comosus cv. Cayene). Ann. Report of Institute of Biotechnology, pp. 42-47. (in Vietnamese with English summary).

Phan Thi Bay, Le Thi Muoi, Nguyen Duc Thanh, 1994b. Cullus culture and plant regeneration from Artemisia annua L. explants. Proc. Nalt. Center Natur. Sci. Tech. Vietnam, 6(1): 61-65.

Phan Thi Bay, Dao Thi Hanh, Quach Thi Lien, Le Thi Muoi, Nguyen Duc Thanh, $2004 \mathrm{c}$. Production of blast resistance and good grain quality rice lines by anther culture and molecular markers. Journal of Biology, 26(3): 48-55. (in Vietnamese with English summary).

Phan Thi Bay, Dao Xuan Hai, Nguyen Duc Thanh, 1996. In vitro propagation of roses. Ann. Report of Institute of Biotechnology, pp. 84-89. (in Vietnamese with English summary).

Phan Thi Bay, Le Thi Muoi, Nguyen Duc Thanh. 1997. The results on blast resistant assay in rice plants derived from calluses resisted to Pyricularia oryzae fungi filtrate. Ann. Report of Institute of Biotechnology, pp. 253-258. (in Vietnamese with English summary).

Phan Xuan Binh Minh, Do Thi Kim Trang, Nguyen Thi Hien, Nguyen Phuong Lan, Tran Bao Tram, 2019. Effect of mineral environment and antimicrobial agent on in vitro propagation of Huperzia serrata Thunb.. Vietnam Journal of Science and Technology, 65(5): 31-36. (in Vietnamese with English summary).
Phan Xuan Huyen, Nguyen Trung Ai, Nguyen Thi Lang, Nguyen Thi Dieu Huong, Dinh Van Khiem, Duong Tan Nhut, 2004. Disease-free plant production and rapid propagation of some Cymbidium cultivars by meristem culture. Journal of Biology, 26(1): 48-54. (in Vietnamese with English summary).

Phan Xuan Huyen, Nguyen Lam Thanh, 2014. Study on in vitro propagation of Codonopsis javanica Blume via axillary shoot culture. Journal of Biotechnology, 12(4): 659-666. (in Vietnamese with English summary).

Phan Xuan Huyen, Tran Thi Hoan Anh, Nguyen Thi Phuong Hoang, Nguyen Thi Thanh Hang, Dinh Van Khiem, Hoang Van Cuong, 2018. In vitro propagation and effect of foliar fertilizer on the growth of Anoectochilus setaceus in Lam Dong. Journal of Medicinal Materials, 23(1): 52-59. (in Vietnamese with English summary).

Phi Hong Hai, Van Thu Huyen, 2016. In vitro propagation of superior families of Acacia (Acacia crassicarpa A. Cunn. Ex Benth.) for forestation. Vietnam Journal of Forestry Science, 3: 4431-4440. (in Vietnamese with English summary).

Phung Thi Hang, Nguyen Bao Toan, 2011. Propagation of Melaleuca cajuputi Powell by tissue culture method. Journal of Science (Can Tho University), 20b: 89-96. (in Vietnamese with English summary).

Quach Thi Lien, Nguyen Duc Thanh, 2003. Preliminary results on plant regeneration from callus of Crinum latifolium $\mathrm{L}$. Journal of Biology, 25(2): 29-34. (in Vietnamese with English summary).

Quach Thi Lien, Nguyen Duc Thanh, 2004. Study on tissue culture conditions of Maesae balansae Mez. for mass production). Journal of Biology, 26(2): 4146. (in Vietnamese with English summary).

Quach Thi Lien, Vu Thi Lan, Le Thi Van Anh, Nguyen Duc Thanh, 2005. Callus 
culture of Crinum latifolium. L. Journal of Biotechnology, 3(3): 353-361. (in Vietnamese with English summary).

Ta Nhu Thuc Anh, Nguyen Thi Bich Thu, 2012. Study on rapid propagation of Celastrus hindsii. Journal of Medicinal Materials, 17(4): 244-247. (in Vietnamese with English summary).

Ta Nhu Thuc Anh, Duong Thi Phuc Hau, Tran Thi Lien, 2014. Study on in vitro propagation of Milletia speciora Champ. Vietnam Journal of Pharmacy, 19(6): 380-384. (in Vietnamese with English summary).

Thi The Luc, Le Trong Lu, Nguyen Du Sanh, Nguyen Thi Quynh, 2017. Organogenesis from in vitro culture of Hydrangea macrophylla "Glowing Embers". Journal of Biotechnology, 15(3A): 161-169. (in Vietnamese with English summary).

Tran Thi Cuc Hoa, Tran Thanh Hai, Ha Minh Luan, Nguyen Tran Hai Bang, Dong Thanh Liem, Ho Thi Huynh Nhu, Le Thi Sol Pha, Bui Thi Bich Hanh, Pham Thi Huong, 2017. Effect of transformation of insect resistance gene in soybean with new vector pHOA60, pH0A100, pH0A130 and resistance to fruit flies of soybean lines carrying VIP $3 A$ gene. Journal of Agriculture and Rural Development, 11: 53-63. (in Vietnamese with English summary).

Tran Thi Dung, Nguyen Huu Ho, 2003. Gene transfer into tobacco plants (Nicotiana tabacum L.) mediated by Agrobacterium tumefaciens. Journal of Biology, 25(1): 55-60. (in Vietnamese with English summary).

Tran Thi Hong Thuy, Do Thi Gam, Nguyen Khac Hung, Pham Bich Ngoc, Chu Hoang $\mathrm{Ha}, 2015$. In vitro micropropagation of an endangered medicinal orchid (Anoectochilus setaceus Blume) through protocorm-like bodies. Journal of Biology, 37(1): 76-83. (in Vietnamese with English summary).

Tran Thi Ngoc Ha, Mai Truong, Phan Tuong Loc, Le Tan Duc, Bui Dinh Thach, Tran
Trong Tuan, Do Dang Giap, Pham Duc Tri, Nguyen Van Ket, Tran Cong Luan, Nguyen Huu Ho, 2013. Production of Ngoc Linh ginseng hair root (Panax vietnamensis $\mathrm{Ha}$ et Grushv.) by Agrobacterium rhizogenes. Journal of Science and Technology, 51(5B): 334-338. (in Vietnamese with English summary).

Tran Thi Luong, Nguyen Thi Thu, Nguyen Thuy Ninh, Nguyen Duc Thanh, 2014. Transferring Shrunken 2 (Sh2) gene coding for ADP-Glucose pyrophosphorylase enzyme into some inbred maize lines by Agrobacterium tumefaciens mediated gene transfer. Journal of Biology, 36(1): 99-109. (in Vietnamese with English summary).

Tran T. L., Ho T. H., Nguyen D. T., 2017. Overexpression of the $\mathrm{IbOr}$ gene from sweet potato (Ipomea batatas 'Hoang Long') in maize increases total carotenoid and $\beta$-carotene contents. Turk. J. Biol., 41: 1003-1010.

Tran Thi Luong, Nguyen Duc Thanh (2018) Enhancing $\beta$-carotene content in maize (Zea mays L.) by transferring IbOr gene involved in carotenoid accumulation. Proceedings National Biotechnology Conference 2018, Hanoi 26/10/2018, pp. 8-13. (in Vietnamese with English summary).

Tran Thi Ngoc Lan, Hoang Van Cuong, Hoang Xuan Chien, Nguyen Ba Nam, Nguyen Du Sanh, Duong Tan Nhut, 2011. Study on Cymbidium Madrit "Forest King" synseeds in propagation and preservation. Journal of Biotechnology, 9(4): 465-474. (in Vietnamese with English summary).

Tran Thi Phuong Lien, Le Xuan Tu, 1993. Preliminary results of the study using Ti plasmid Agrobacterium tumefaciens to transform GUS and antibiotic resistance genes into tobacco plant. Journal of Biology, 15(2): 34-38. (in Vietnamese with English summary).

Tran Thi Xuan Mai, Tran Thi Cuc Hoa, 2017. Development of lysine-rich rice by gene transfer through Agrobacterium. 
Journal of Agriculture and Rural Development, 9: 82-89. (in Vietnamese with English summary).

Tran Trong Tuan, Nguyen Huu Ho, Duong Tan Nhut, 2015. Effect of gibberellic acid, proline and spermidine on the formation of flower buds of in vitro cultured Torenia fournieri L. Journal of Biotechnology, 13(1): 123-130. (in Vietnamese with English summary).

Tran Van Minh, 1997. Clonal propagation of Artocarpus heterophyllus Lam. By apical shoot tip. Journal of Biology, 19(2): 51-55. (in Vietnamese with English summary).

Tran Van Thinh, Phan Xuan Huyen, Cao Dinh Hung, 2015. Application of artificial seeds for in vitro propagation and storage of Codonopsis javanica Blume). Journal of Biotechnology, 13(1): 83-91. (in Vietnamese with English summary).

Trieu Thi Thu Ha, Can Thi Lan, Dong Thi Ung, 2014. Propagation of Acacia auriculiformis A. Cunn. Ex Banth by cell tissue culture method. Vietnam Journal of Forest Science, 4: 3508-3515. (in Vietnamese with English summary).

Trinh Manh Dung, Phan Xuan Thanh, Doan Thi Ai Thuyen, Nguyen Van Uyen, 1986. Produce and maintain in vitro haploid rice plants. Journal of Biology, 8(1): 15-18. (in Vietnamese with English summary).

Trinh Thi Huong, Duong Tan Nhut, 2011. In vitro germination of somatic embryoderived artificial seed of Ngoc Linh ginseng (Panax vietnamensis $\mathrm{Ha}$ et Grushv.). Journal of Biotechnology, 9(4): 443-453. (in Vietnamese with English summary).

Trinh Thi Huong, Vu Quoc Luan, Nguyen Phuc Huy, Nguyen Ba Nam, Tran Trong Tuan, Nguyen Xuan Tuan, Nguyen Thi Thuy Anh, Duong Tan Nhut, 2013. Effects of $\mathrm{GA}_{3}, \mathrm{NAA}$ and $\mathrm{BA}$ supplementation to the matrix or in culture medium on germination of artificial seeds of Panax vietnamensis Ha et Grushv. Journal of Biotechnology, 11(4): 681-687.
Trinh Thi Huong, Nguyen Hong Hoang, Vu Thi Hien, Hoang Thanh Tung, Nguyen Ba Nam, Nguyen Phuc Huy, Vu Quoc Luan, Bui The Vinh, Tran Dinh Phuong, Lam Diep Thao, Pham Bich Ngoc, Tran Cong Luan, Chu Hoang Ha, Duong Tan Nhat, 2015. Influences of elicitors on the growth and saponin accumulation of Panax vietnamensis $\mathrm{Ha}$ et Grushv. transgenic hairy roots. Journal of Biotechnology, 13(3): 843-851. (in Vietnamese with English summary).

Trinh Thi Lan Anh, Le Kim Cuong, Nguyen Phuc Huy, Nguyen Ba Nam, Trinh Thi Huong, Vu Thi Hien, Vu Quoc Luan, Vo Thi Bach Mai, Duong Tan Nhut, 2013. Effects of different sugars on somatic embryogenesis of Phaleanopsis amabilis. Journal of Biotechnology, 11(3): 529-537. (in Vietnamese with English summary).

Trinh Thi Thuy An, Nguyen Thi Tam, 2017. In vitro propagation of Dendrobium offcinale Kimura et Migo. Journal of Science and Technology (Thai Nguyen University), 161(1): 69-72. (in Vietnamese with English summary).

Trinh Viet Nga, Nguyen Duc Minh Hung, Bui Minh Tri, Ngo Thi Anh Khoi, Trieu Thi Bich, Pham Thi Minh Tam, Nguyen Huu Ho, 2019. In vitro culture of somatic embryos of Polyscias fruticosa (L.) Harms) on a liquid shaking culture system. Journal of Agriculture and Rural Development, 5: 25-34. (in Vietnamese with English summary).

Truong Thi Bich Phuong, Truong Nu Gia Ai, Nguyen Hoang Loc, Nguyen Huu Dong, 2002. Selection of rice lines (Oryza sativa L.) that are drought tolerant through callus culture. Journal of Agriculture and Rural Development, 7: 579-580. (in Vietnamese with English summary).

Truong Thi Bich Phuong, Tran Thi Kim Thu, Nguyen Hoang Loc, 2008. In vitro propagation of Polygonum multiflorum Thunb. Journal of Biotechnology, 4(4b): 889-895. (in Vietnamese with English summary). 
Truong Thi Bich Phuong, Phan Ngoc Khoa, 2013. In vitro propagation of Anoectochilus roxburghii (Wall.) Lindl. Hue University Journal of Science, 79(1): 41-46. (in Vietnamese with English summary).

Vi Thi Xuan Thuy, Lo Thi Mai Thu, Ho Manh Tuong, Le Van Son, Nguyen $\mathrm{Vu}$ Thanh Thanh, Chu Hoang Mau, 2016. Characteristics of defensin1 gene and designing structure to create resistant transgenic corn lines to weevils. Journal of Biotechnology, 14(2): 279-286. (in Vietnamese with English summary).

Vi T. X. T., Le H. D., Nguyen V. T. T., Le V. S., Chu H. M., 2017. Expression of the ZmDEF1 gene and $\alpha$-amylase inhibitory activity of recombinant defensin against maize weevils. Turk. J. Biol., 41: 98-104.

$\mathrm{Vu}$ Hoai Sam, Pham Van Hien, Nguyen Ba Hoat, 2005. Rapid in vitro propagation of Polyscias fruticosa by apical buds. Journal of Medicinal Materials, 10(5): 135-137. (in Vietnamese with English summary).

Vu Hoai Sam, Duong Thi Phuc Hau, Ta Nhu Thuc Anh, Nguyen Thi Huong, Pham Thanh Huyen, Nguyen Minh Khoi, 2016. In vitro conservation of Dendrobium nobile Lindl. and Anoectochilus setaceus Blume. by slow growth culture. Journal Medicinal Materials, 21(3): 204-208. (in Vietnamese with English summary).

Vu Hoai Sam, Nguyen Thi Xuyen, Duong Thi Ngoc Anh, Hoang Thi Nhu Nu, Nguyen Thi Huong, Le Xuan Thao, Ngo Thi Mai Anh, Phan Thuy Hien, 2018. Research on micropropagation of Rehmannia glutinosa (Gaertn.) Libosch. Journal of Medicinal Materials, 23(6): 374-379. (in Vietnamese with English summary).

Vu Kim Dung, Nguyen Van Viet, Bui Van Thang, 2016. Propagation of Dendrobium gratiosisstimum Reichenb. F. by in vitro culture technique. Journal of Forestry Science and Technology, 6: 156-161. (in Vietnamese with English summary).

Vu Ngoc Lan, Nguyen Thi Ly Anh, 2013. In vitro propagation of native orchid species
Dendrobium nobile L.. Journal of Science and Development, 11(7): 917-925. (in Vietnamese with English summary).

$\mathrm{Vu}$ Ngoc Phuong, Pham Duc Tri, Thai Xuan Du, Nguyen Van Uyen, 2000. Propagation of Azadirachta indica A. Juss by tissue culture. Journal of Biology, 22(2): 34-39. (in Vietnamese with English summary).

Vu Ngoc Phuong, Pham Duc Tri, Doan Thi Ai Thuyen, Trinh Viet Nga, Tran Xuan Du, Nguyen Van Uyen, 2002. Micropropagation of two bamboo species Sinocalamus latiflorus and Dendrocalamus asper by tissue culture. Journal of Biology, 24(2): 59-64. (in Vietnamese with English summary).

$\mathrm{Vu}$ Ngoc Phuong, Hoang Thi Phong, Thai Xuan Du, Trinh Manh Dung, 2009. In vitro propagation of banana trees (Cavendish sp.) on an industrial scale. Scientific report-National Biotechnology Conference 2009, Biotechnology for Agriculture-Forestry, Fishery, Industry, Medicine and Pharmacy and Environmental Protection; Thai Nguyen, November 26-27, 2009, pp. 319-322. (in Vietnamese with English summary).

Vu Quoc Luan, Nguyen Phuc Huy, Hoang Xuan Chien, Trinh Thi Huong, Vu Thi Hien, Nguyen Ba Nam, Do Khac Thinh, Duong Tan Nhut, 2012. Micropopagation of Paphiopedilum callosum. Journal of Biotechnology, 10(3): 497-505. (in Vietnamese with English summary).

Vu Quoc Luan, Nguyen Phuc Huy, Do Khac Thinh, Duong Tan Nhut, 2013a. In vitro propagation of Paphiopedilum graxtrixianum through protocorm-like body induction from seeds. Journal of Biotechnology, 11(3): 521-528. (in Vietnamese with English summary).

$\mathrm{Vu}$ Quoc Luan, Nguyen Phuc Huy, Nguyen Ba Nam, Vu Thi Hien, Do Khac Thinh, Duong Tan Nhut, 2013b. Stem elongation technique in micropropagation of Paphiopedilum callosum. Journal of Biotechnology, 11(4): 717-726. (in Vietnamese with English summary). 
Vu Quoc Luan, Tran Dinh Phuong, Tran Cong Luan, Duong Tan Nhut, 2015. Micropropagation and $\beta$-Sitosterol qualitative research on Anoectochilus setaceus Blume. Journal of Biotechnology, 13(4): 1113-1125. (in Vietnamese with English summary).

Vu Q. L., Le K. C., Hoang T. T., Vu T. H., Tran H., Duong T. N., 2019. Effects of shoot tip removal, wounding manipulation, and plant growth regulators on shoot regeneration and plantlet development in Paphiopedilum species. Sci. Hortic., 256: 1-6.

Vu Thi Bich Huyen, Phan Xuan Hao, Vuong Huy Minh, Nguyen Duc Thanh, 2013. Plant generation from immature embryos of Vietnamese maize lines. Journal of Biotechnology, 11(2): 255-264. (in Vietnamese with English summary).

Vu Thi Hien, Vu Quoc Luan, Nguyen Phuc Huy, Nguyen Ba Nam, Bui Van The Vinh, Thai Xuan Du, Duong Tan Nhut, 2014. Direct embryogenesis from leaves, petioles and roots of Ngoc Linh ginseng (Panax vietnamensis $\mathrm{Ha}$ et Grushv.). Journal of Biology, 36(1se): 277-282. (in Vietnamese with English summary).

$\mathrm{Vu}$ Thi Hien, Vu Quoc Luan, Nguyen Phuc Huy, Nguyen Ba Nam, Nguyen Thi Kim Loan, Nguyen Thanh Sang, Vu Thi Thuy, Nguyen Hong Hoang, Thai Xuan Du, Duong Tan Nhut, 2015. Using thin cell layer culture technique to study in vitro morphogenesis of Ngoc Linh ginseng (Panax vietnamensis $\mathrm{Ha}$ et Grushv.). Journal of Science and Development,
13(4): 661-669. (in Vietnamese with English summary).

$\mathrm{Vu}$ Thi Hien, Nguyen Phuc Huy, Bui Van The Vinh, Hoang Xuan Chien, Hoang Thanh Tung, Nguyen Ba Nam, Vu Quoc Luan, Duong Tan Nhut, 2016. Somatic embryogenesis from leaf transverse thin cell layer derived-callus of Vietnamese ginseng (Panax vietnamensis $\mathrm{Ha}$ et Grushv.). Journal of Biotechnology, 14(1): 63-73.

$\mathrm{Vu}$ Thi Lan, Quach Thi Lien, Nguyen Duc Thanh, 2008. Effect of growth regulator combinations and casein on callus biomass of Crinum latifolium L.. Journal of Biotechnology, 6(1): 97-106. (in Vietnamese with English summary).

Vu Thi Lan, Nguyen Thi Nga, Nguyen Dinh Trong, Pham Bich Ngoc, Chu Hoang Ha, Le Tran Binh, 2013. The efficiency of $\mathrm{ABA}$ and GA3 on process of multiple shoot induction from calli of sweet potato Ipomoea batatas (L.) Lam. Journal of Biotechnology, 11(4): 727-734. (in Vietnamese with English summary).

Vu Thi Lan, Pham Bich Ngoc, Chu Hoang Ha, Le Tran Binh, 2018. Agrobacteriummediated transformation of cry $3 C A 1$ gene into KB1 sweet potato cultivar. Journal of Biology, 40(2): 252-258. (in Vietnamese with English summary).

$\mathrm{Vu}$ Thi Thu Thuy, Nguyen Thi Tam, Chu Hoang Mau, 2013. Generation of peanut line with drought tolerance by plant cell technology. Journal of Biology, 35(3): 357-362. (in Vietnamese with English summary). 